\title{
A combined literature and in silico analysis enlightens the role of the NDRG family in the gut
}

Citation for published version (APA):

Vaes, N., Schonkeren, S. L., Brosens, E., Koch, A., McCann, C. J., Thapar, N., Hofstra, R. M. W., van Engeland, M., \& Melotte, V. (2018). A combined literature and in silico analysis enlightens the role of the NDRG family in the gut. Biochimica et Biophysica Acta-general Subjects, 1862(10), 2140-2151. https://doi.org/10.1016/j.bbagen.2018.07.004

Document status and date:

Published: 01/10/2018

DOI:

10.1016/j.bbagen.2018.07.004

Document Version:

Publisher's PDF, also known as Version of record

Document license:

Taverne

Please check the document version of this publication:

- A submitted manuscript is the version of the article upon submission and before peer-review. There can be important differences between the submitted version and the official published version of record.

People interested in the research are advised to contact the author for the final version of the publication, or visit the DOI to the publisher's website.

- The final author version and the galley proof are versions of the publication after peer review.

- The final published version features the final layout of the paper including the volume, issue and page numbers.

Link to publication

\footnotetext{
General rights rights.

- You may freely distribute the URL identifying the publication in the public portal. please follow below link for the End User Agreement:

www.umlib.nl/taverne-license

Take down policy

If you believe that this document breaches copyright please contact us at:

repository@maastrichtuniversity.nl

providing details and we will investigate your claim.
}

Copyright and moral rights for the publications made accessible in the public portal are retained by the authors and/or other copyright owners and it is a condition of accessing publications that users recognise and abide by the legal requirements associated with these

- Users may download and print one copy of any publication from the public portal for the purpose of private study or research.

- You may not further distribute the material or use it for any profit-making activity or commercial gain

If the publication is distributed under the terms of Article $25 \mathrm{fa}$ of the Dutch Copyright Act, indicated by the "Taverne" license above, 
Review

\title{
A combined literature and in silico analysis enlightens the role of the NDRG family in the gut
}

\author{
Nathalie Vaes ${ }^{\mathrm{a}}$, Simone L. Schonkeren ${ }^{\mathrm{a}}$, Erwin Brosens ${ }^{\mathrm{b}}$, Alexander Koch ${ }^{\mathrm{a}}$, Conor J. McCann ${ }^{\mathrm{c}}$, \\ Nikhil Thapar ${ }^{\mathrm{c}}$, Robert M.W. Hofstra ${ }^{\mathrm{b}}$, Manon van Engeland ${ }^{\mathrm{a}}$, Veerle Melotte ${ }^{\mathrm{a}, \mathrm{b}, *}$ \\ ${ }^{a}$ Department of Pathology, GROW-School for Oncology and Developmental Biology, Maastricht University Medical Center, The Netherlands \\ ${ }^{\mathrm{b}}$ Department of Clinical Genetics, University of Rotterdam, EMC, Rotterdam, The Netherlands \\ ' Stem Cells and Regenerative Medicine, UCL Great Ormond Street Institute of Child Health, London WC1N, UK
}

\section{A R T I C L E I N F O}

\section{Keywords:}

Biomarkers

Colorectal cancer

Intestinal tract

$\mathrm{N}$-myc downstream-regulated gene

Tumor suppressors

\begin{abstract}
A B S T R A C T
Background: The N-Myc Downstream-Regulated Gene (NDRG) family comprises four members that function in cellular processes like proliferation and differentiation. While NDRG1 and NDRG2 are extensively studied, knowledge regarding NDRG3 and NDRG4, despite its recognition as a well-established early-detection marker for colorectal cancer (Cologuard ${ }^{\circledR}$ ), is sparse.

Scope of review: To summarize expression, biomarker potential and functional mechanisms of the NDRGs in the developing, mature and cancerous gut, we combine current literature and in silico analyses from the TCGAdatabase, GTEX Project, E14.5 mouse intestine and enteric neural crest cells, and an RNA-sequencing time-series of human embryonic colonic samples.

Major conclusions: This study reveals that all members display a differential expression pattern in the gut and that NDRG1, NDRG2 and NDRG4 (1) can serve as biomarker for colorectal cancer and (2) have tumor suppressive properties mainly affecting cell proliferation and epithelial-mesenchymal transition.

General significance: Similar effects of the NDRGs on the key-hallmarks of cancer, could implicate analogous functions in other tissue/cancer types.
\end{abstract}

\section{Introduction}

The N-myc downstream-regulated gene $(N D R G)$ family is composed of four members: NDRG1, NDRG2, NDRG3 and NDRG4, and owes its name to the discovery of the first member, $N D R G 1$, as being repressed by the $C-M y c$ and $N-M y c$ oncogenes [1]. In humans and mice, the four genes are all located on different chromosomes. Various aliases have been designated to each family member and each gene is transcribed into multiple alternatively spliced mRNA transcripts that encode several protein isoforms [2]. The encoded proteins of this family are all characterized by an NDR region and an $\alpha / \beta$ hydrolase fold, but lack the catalytic motif required to be enzymatically active [3,4]. The NDRG proteins which share about $52-65 \%$ sequence homology with an identical C-terminal sequence "MEVSC" and only very few sequence differences primarily in the $\mathrm{C}$ - and $\mathrm{N}$-terminal regions, have been shown to be highly conserved in a variety of species [5,6]. More detailed information about the general knowledge on the NDRG family members, with respect to structure, origin and signaling in physiological processes can be found in our former review by Melotte et al. [2].

Previously, we and various independent groups identified NDRG4 promoter CpG island methylation in fecal DNA as an accurate early-detection marker for colorectal cancer (CRC) [7-16]. The

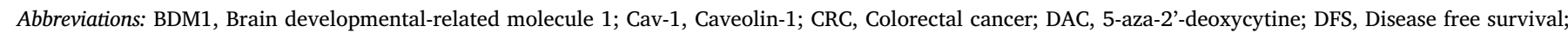

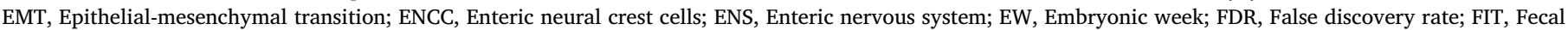

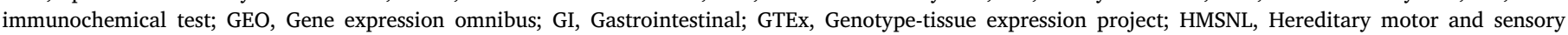

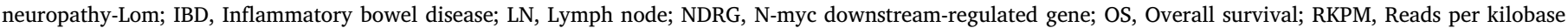

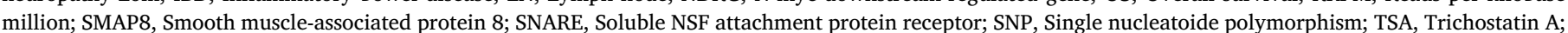
TCGA, The cancer genome atlas; TSS, Transcription start site; UC, Ulcerative colitis; VAMP, Vesicle-associated membrane protein

* Corresponding author at: Dept. of Pathology, GROW - School for Oncology and Developmental Biology, Maastricht University Medical Center, P.O. Box 616, 6200 MD, Maastricht, The Netherlands.

E-mail addresses: n.vaes@maastrichtuniversity.nl (N. Vaes), s.schonkeren@student.maastrichtuniversity.nl (S.L. Schonkeren), e.brosens@erasmusmc.nl (E. Brosens), a.koch@maastrichtuniversity.nl (A. Koch), conor.mccann@ucl.ac.uk (C.J. McCann), n.thapar@ucl.ac.uk (N. Thapar), r.hofstra@erasmusmc.nl (R.M.W. Hofstra), m.vanengeland@maastrichtuniversity.nl (M. van Engeland), veerle.melotte@maastrichtuniversity.nl (V. Melotte). 
biomarker performance of NDRG4 was further exploited by Exact Sciences, who integrated NDRG4 promoter methylation into a multi-target stool DNA test: Cologuard ${ }^{\circledR}$ (Madison, USA) [16]. This FDA-approved stool DNA test detects significantly more CRCs and advanced precancerous lesions than the leading fecal immunochemical test (FIT) and is currently used in the USA for CRC screening [7]. Despite being incorporated into the Cologuard $^{\circledR}$, almost nothing is known about the function(s) of NDRG4 in the (diseased) intestinal tract. Whereas NDRG1 and NDRG2 are important in various cellular processes (e.g. proliferation, differentiation, apoptosis), little is known about NDRG3 and NDRG4.

Here, we performed a literature search (Pubmed, Web of Science, Embase and Medline) and supported this literature search with in silico data extracted from (i) publicly available transcriptome databases [17,18], (ii) previously generated transcriptome data of E14.5 mouse intestine and enteric neural crest cells (ENCCs) [19] and (iii) an RNA-sequencing time-series of human embryonic colonic samples, to gain more insights into the expression pattern, biomarker potential and common pathways of the NDRGs in the intestinal tract.

Our review indicates that NDRG1, NDRG2 and NDRG4 can act as biomarkers for CRC. Although there is no evidence that the different family members are major drivers in the development of CRC, data suggest that, except for NDRG3, each NDRG member has a protective role during intestinal carcinogenesis.

\section{Expression pattern of the NDRGs in the developing and adult gut}

To understand the functional importance of the NDRG family members in the intestinal tract, we first elaborate on their structure and summarize their (overlapping) intestinal-specific expression pattern in mammalian species like rat, mouse and human.

In humans, NDRG1 is located on chromosome $8 \mathrm{q} 24.3$, while the mouse ortholog is located on chromosome 15D2. The encoded canonical protein sequence of human NDRG1 (DRG1, RTP, RIT42, CAP43) consists of 394 amino acids (AA), resulting in a $43 \mathrm{kDa}$ protein. The two other isoforms are made up of 328 and $313 \mathrm{AA}$, with a respective mass of 35.5 and $34 \mathrm{kDa}$. In mouse and rat, only one isoform has been found, with a similar length as the human canonical protein sequence and minor AA differences.

The expression of the NDRG1 gene usually coincides in tissues where $N$-myc is expressed, but only initiates at E9.5 as the intestinal epithelium begins to differentiate and $N$-myc expression decreases [20]. As further intestinal development requires retinoic acid-dependent activation of NDRG1 and suppression of the Wnt/ $\beta$-catenin pathway [21], $N D R G 1$ mRNA expression steadily increases in the mouse and human intestinal epithelium from E10.5 onwards [20]. Further intestinal maturation in rodents and humans seems to be controlled by circulating levels of glucocorticoids and cortisol, respectively [22], giving rise to similar levels of NDRG1 in the adult small and large intestine [5,22-24]. Moreover, the expression of NDRG1 mRNA and protein is induced by glucocorticoid treatment (i.e. by dexamethasone) and strongly overlaps with a gradual increase from crypt cells towards surface cells $[20,22,24,25]$. On a sub-cellular level, NDRG1 is primarily localized in the cytoplasm of epithelial cells, where it is often associated with the basolateral membrane adjacent to adherens junctions and desmosomes [20,24,26].

NDRG2 is located on chromosome 14q11,2 and 14C1 in human and mouse, respectively. The main functional form of human, mouse and rat NDRG2 (SYLD, NDR2) is either a $41 \mathrm{kDa}$ protein, composed of $371 \mathrm{AA}$, or a $39 \mathrm{kDa}$ protein of $357 \mathrm{AA}$. In addition, there are four other human isoforms with a length ranging from 328 to $367 \mathrm{AA}$ and a variable mass between 36 and $40.3 \mathrm{kDa}$.

In early developmental stages (E8.5-9.5) the poorly differentiated intestinal epithelium expresses low levels of NDRG2 mRNA and protein. From E10.5 towards adulthood, the levels of NDRG2 mRNA and protein very slightly increase in the mucous forming, lining epithelial cells [20,27], leading to barely detectable levels in adult gut tissue. Even though most studies observed a slightly higher level of NDRG2 mRNA in the (distal) colon compared to the small intestine [5,28,29], contradictory observations regarding NDRG2 protein expression have been described. Yamamoto et al. detected a marginally higher signal in colon than in the small intestine [30], whereas Hu et al. detected opposite results with weak to moderate NDRG2 immunoreactivity in the small intestine but not in the colon [31].

Human chromosome 20q11.21-11.32 and mouse chromosome 2H1 contain the NDRG3 gene, which can be transcribed into three identified protein isoforms. The canonical sequence of $N D R G 3$ (no known aliases) encodes a $41.5 \mathrm{kDa}$ protein of $375 \mathrm{AA}$ in various mammalian species. The second and third isoform are only found in humans and encode a $40 \mathrm{kDa}$ protein of $363 \mathrm{AA}$ and a markedly lighter protein $(31.5 \mathrm{kDa})$ of only 286 AA.

Only three studies include a brief description about the expression of NDRG3. In fact, in situ mRNA hybridization (ISH) and Northern Blotting reveal that NDRG3 expression is already activated at E9.5 and that NDRG3 is widely expressed during embryogenesis. However no NDRG3 mRNA is detected in the developing intestinal tract [20]. During further development, overall NDRG3 mRNA and protein levels increase slightly, although they are hardly detectable in matured mouse and human gut tissues [5,30].

The NDRG4 gene is situated on human chromosome 16q21-q22.1 and mouse chromosome 8D1. For NDRG4 (SMAP8, BDM1), the canonical protein sequence is referred to as NDRG4B ${ }^{\text {var }}$, consisting of 352 AA (39 kDa). The two other main isoforms are NDRG4B and NDRG4H which contain $339 \mathrm{AA}$ (37 kDa) and $371 \mathrm{AA}(41 \mathrm{kDa})$, respectively. In addition, 5 other isoforms can be produced by alternative splicing, with sequences ranging from 339 to $391 \mathrm{AA}$ (37-43 kDa). In mouse, we recently identified three isoforms, corresponding to human NDRG4B ${ }^{\text {var }}$ (long isoform), NDRG4B (short isoform) and NDRG4H [32]. Furthermore, rat tissues express an additional fourth isoform of $45 \mathrm{kDa}$, encoded by the rat ortholog: SMAP8/BDM1 [33].

So far, the pattern of NDRG4 expression during embryonic gut development has not yet been described. In adult tissues however, current literature is inconsistent regarding the intestinal-specific expression pattern of NDRG4 which can be attributed to the use of different, aspecific commercially-available antibodies [32]. We and Chu et al. previously described that NDRG4 is expressed within epithelial cells of the gut [12,34] and Qu et al. found high NDRG4 protein levels in smooth muscle cells of the stomach [35]. However, we recently observed that the anti-NDRG4 antibody used in these studies was not specifically targeting NDRG4 [32]. The experimental application of an antibody that specifically targets NDRG4 has demonstrated that NDRG4 expression in the gut is restricted to the cytoplasm of neuronal cell bodies and nerve fibers belonging to the nervous system of the gut, i.e. the enteric nervous system (ENS) [32].

\subsection{In silico expression analysis}

To clarify the discrepancies concerning the NDRG expression pattern in the developing/mature gut observed in the limited number of publications, we evaluated expression data from the (i) GTEx Project (06/19/2017), (ii) previously generated transcriptome data of E14.5 mouse intestine and ENCCs (available in the Gene Expression Omnibus (GEO); GSE34208) [19] and (iii) an RNA seq time-series of human embryonic full-thickness samples of proximal colon (Embryonic Week (EW) 12, EW14 and EW16; data generated by the group of Prof. Thapar (UCL, London) and deposited to GEO).

Compared to its family members, NDRG1 is highly expressed in EW12, EW14 and EW16 human colonic samples, with levels (in reads per kilobase million, RPKM) being 10, 8 and 12 times higher than for NDRG2, 3 and 4, respectively (Fig. 1A). In addition, NDRG1 shows the highest and intercomparable expression in sections of the mature small 
A

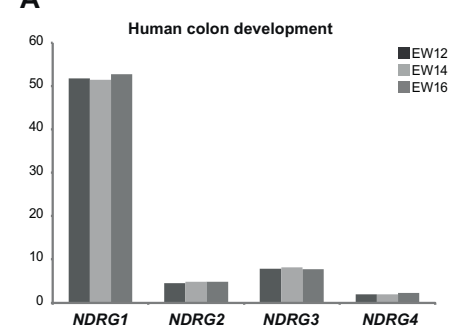

E

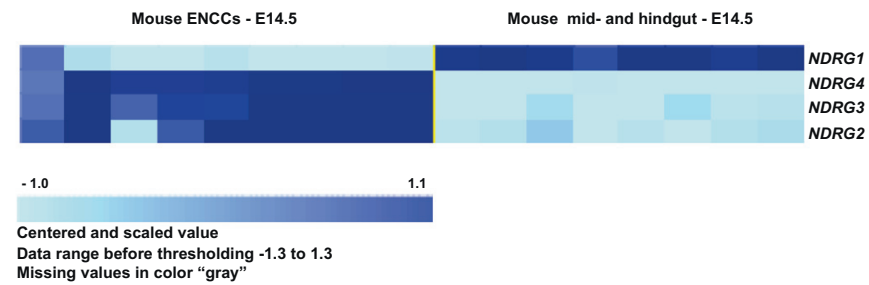

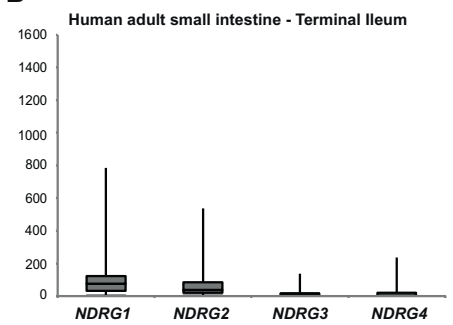

C

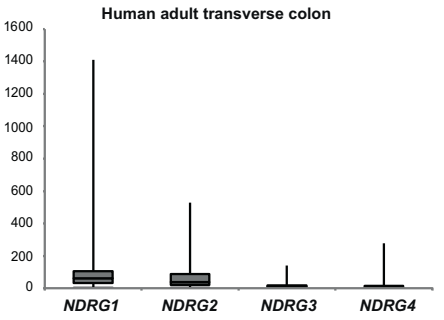

D

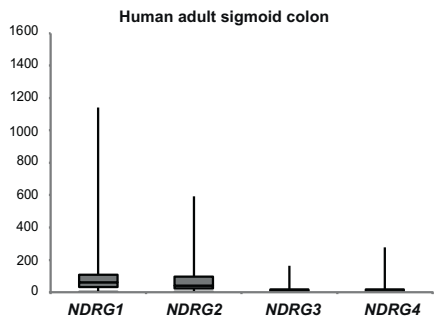

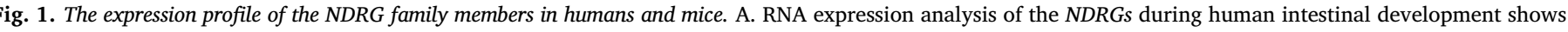

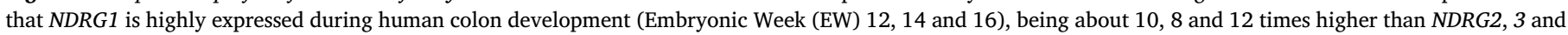

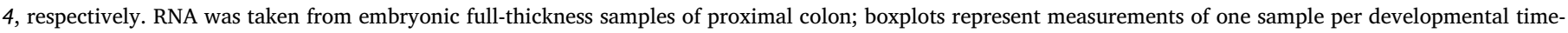

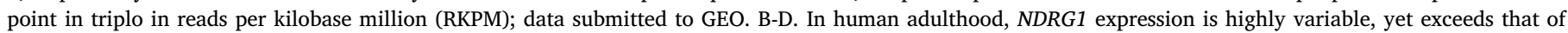

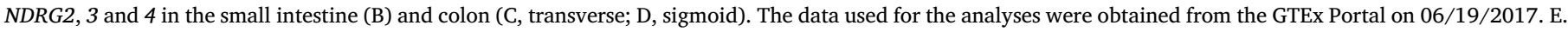

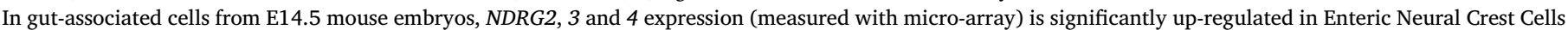

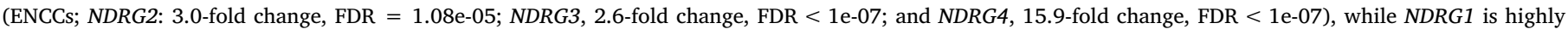
expressed and slightly up-regulated in the total gut $(0.11$-fold change, FDR < 1e-07).

intestine (Fig. 1B, terminal ileum) and colon (Fig. 1C-D, transverse and sigmoid). Using the RNA expression data set, we observed that NDRG2 is expressed in low levels in human embryonic intestine, similar as described by Okuda et al. and Hu et al. [20,27] (Fig. 1A). In contrast to $N D R G 1$, little NDRG2 mRNA is detectable in the adult human intestinal tract, which is only marginally different in small intestinal and colonic tissues (Fig. 1B-D). These very low expression levels may account for the in-literature-described inconsistencies of intestinal NDRG2 protein expression being either increased or decreased in colon versus small intestine.

Similar as observed for NDRG2, little NDRG3 mRNA is detectable in the developing and mature human intestinal tract. In fact, NDRG3 mRNA levels in embryonic and adult human intestines are about eight and seven-fold lower compared to NDRG1 (Fig. 1A).

While no literature describes the pattern of NDRG4 expression during intestinal development, our analysis shows that of the four members, NDRG4 has the lowest mRNA level in human embryonic gut tissues. In humans, NDRG4 expression in the embryonic bowel is approximately twelve times lower compared to NDRG1 (Fig. 1A). Consequently, only low to intermediate levels of NDRG4 can be detected in whole-gut tissues of adult humans (Fig. 1C). Interestingly, as we recently observed that NDRG4 is exclusively located in structures of the ENS [32], we wondered whether NDRG4 expression in early developmental stages is also found in structures that will form the ENS, i.e. the enteric neural crest cells (ENCCs). Therefore, we compared the expression of the NDRGs in whole-gut biopsies with ENCCs, which we previously isolated from E14.5 mouse intestine [19]. Corresponding with its ENS-specific expression in adult gut, NDRG4 mRNA is significantly higher expressed in ENCCs compared to total gut tissue of E14.5 mouse embryos (Fig. 1E; 15.88 fold change, FDR < 1e-07). Thus, it can be stated that NDRG4 is continuously expressed by ENCCs upon colonization of the gut and development into the ENS upon intestinal maturation, which accounts for the low level of expression in whole-gut tissues of adult mice/humans. This raised the question if the other family members are also expressed uninterruptedly within the epithelial cells or ENCCs throughout development. When comparing the expression analyses of whole-gut biopsies and ENCCs, we observed that
NDRG1 is hardly detectable in ENCCs, but highly expressed in embryonic and mature mouse and human total gut samples (Fig. 1A, E; fold change 0.11, FDR < 1e-07; Fig. 1B-D) [19]. These data, combined with the in literature-described expression of NDRG1 in the (developing) epithelial layer, suggests that NDRG1 remains mainly expressed within the epithelium throughout intestinal maturation. On the other hand, the expression of NDRG2 and NDRG3 is respectively 3.0 and 2.57fold higher in ENCCs compared to total gut tissue of E14.5 mouse embryos (Fig. 1E; FDR NDRG2 = 1.08e-05 and FDR NDRG3 < 1e-07). Thus, besides valid concerns on whether different anti-NDRG2/3 antibodies or experimental procedures are specific enough for the identification of NDRG2/3 in adult gut, it is also possible that the expression of NDRG2/3 shifts towards the epithelial cells upon further intestinal maturation. Hence, further investigation is needed to unravel if NDRG2 and NDRG3 expression is retained in ENCCs and appears in the ENS or rather moves to the epithelial cells during gut development.

\section{Differential expression levels during intestinal carcinogenesis}

Multiple studies have investigated changes in NDRG mRNA and protein expression in neoplastic (adenomas, primary tumors, metastatic lesions, intestinal cancer cell lines) compared to normal tissue, which we further explored using the publicly available TCGA data. Moreover, we used current literature and TCGA data to identify possible mechanisms that regulate the differential expression of the NDRGs during intestinal carcinogenesis.

\subsection{Differential expression levels}

While the limited knowledge on NDRG3 in the healthy gut hinders further evaluation of NDRG3 expression during intestinal diseases, several studies discuss the differential expression of NDRG1, NDRG2 and NDRG4 during colorectal carcinogenesis. However, studies that described changes in NDRG4 protein levels are based on the inaccurate detection of NDRG4 (as described above [12,34,36]) and are thus not further taken into account here.

Only four studies described normal or increased levels (i.e. preserved 
levels) of NDRG1 expression in tumor tissues compared to normal tissues [37-40]. Nevertheless, six studies agree on significantly reduced mRNA and protein levels of NDRG1 [23,26,40-43], but also NDRG2 [44-50], and NDRG4 [12,51] in neoplastic tissues compared to healthy colonic epithelium. Moreover, mRNA and protein levels of both NDRG1 and NDRG2 decrease with increasing tumor grade: NDRG1 and NDRG2 are highly expressed in normal and low-risk adenoma tissue and show a gradual decrease from well- to moderately to poorly or undifferentiated tumor tissue and to metastatic lesions [23,26,41,43-50]. These findings are further supported by several in vitro studies demonstrating (i) the high expression of NDRG1 in the normal colon epithelial cell line NCM460 and the low expression of NDRG1 and NDRG4 in several colon cancer cell lines (e.g. HCT116, SW480, RKO) [12,52], (ii) the higher level of NDRG1 and NDRG2 in primary colon cancer cell lines (e.g. HCT116 and SW480) compared to metastatic colon cancer cell lines (e.g. SW620, Lovo) [23,46,53], (iii) the up-regulation of both NDRG1 and NDRG2 upon differentiation (e.g. by N-acetyl-L-cysteine) of primary colon cancer cell lines (e.g. HT29) $(23,26,55,60)$, and (iv) the induction of morphological changes and increased expression of important epithelial cell differentiation markers by NDRG1 overexpression in metastatic colon cancer cells [23,54].

Using data from the publicly available TCGA database containing 261 colorectal cancer patients and 41 colonic healthy controls we further investigated the expression of all four NDRG members in cancerous compared to healthy colon tissue (Fig. 2A). While no literature describes NDRG3 expression during colorectal carcinogenesis, the TCGA data reveal that the expression is only marginally, but not significantly up-regulated in CRC tumors compared to normal colon (Fig. 2A). Moreover, in agreement with most literature studies, the level of NDRG1, NDRG2 and NDRG4 mRNA is significantly reduced in colorectal tumor tissue compared to normal colonic tissue (Fig. 2A; Wilcoxon rank sum test, all $\mathrm{P}<0.001)$. Consequently, it is thus extremely likely that NDRG1 protein levels will also be reduced during CRC and that above described discrepancies (i.e. lower vs. higher expression in tumor tissue) can be attributed to the usage of different (non-) commercially available anti-NDRG1 antibodies or variations in experimental procedures, yet are most presumably explained by the highly variable outcome of NDRG1 positivity measurements, using different variations of a semi-quantitative measurement method (i.e. a calculation of NDRG1-positive cells per area (\%) combined with a score reflecting the intensity of NDRG1 immunoreactivity (0-3)).

\subsection{Causes of NDRG loss}

\subsubsection{Genetic changes}

Only sporadically, mutations for NDRG family members have been identified. So far no studies have investigated whether NDRG1 is mutated during colorectal tumorigenesis, while it is well-described that NDRG1 mutations lead to hereditary motor and sensory neuropathy-Lom (HMSNL), a severe autosomal recessive peripheral neuropathy (Charcot-Marie-Tooth disease) [55]. Further, there is no evidence for (in)activating mutations of NDRG2, NDRG3 and NDRG4 throughout the course of CRC in current literature, and the single-nucleotide polymorphisms (SNPs) that affect NDRG4 in 75-100\% of primary colorectal cancers, do not alter its AA sequence [12]. Similarly, we found little evidence for cancer-related mutations in any of the NDRG genes in the publicly available TCGA mutation data: NDRG1: 2/154 (missense mutation and silent SNP), NDRG2: 6/154 (2 missense mutations and 4 silent SNPs), NDRG3: 1/154 (missense mutation) and NDRG4: 2/154 (intron SNP and frame shift mutation).

Chromosomal imbalances have also been shown to play a role in the pathogenesis of stromal tumors of the gastrointestinal (GI) tract. During colorectal carcinogenesis no chromosomal disparities containing NDRG1 have been described. Although Ässämäki et al. and Lorentzen et al. have identified that copy number changes might affect NDRG2 in tumors of the GI tract, the first study shows that NDRG2 is the most commonly deleted region at $14 \mathrm{q} 11.2$ in GI tumors [56], whereas the latter recently revealed that allelic loss of NDRG2 is less frequent than a copy number gain in CRC [57]. For NDRG4, we previously observed loss of heterozygosity in $27 \%$ of CRCs [12]. As described above, alterations in NDRG3 have not been examined during intestinal diseases in literature. Nonetheless, analysis of the TCGA copy number data (Fig. 2B) revealed a significant copy number gain for NDRG1 and NDRG3 in tumor compared to normal samples $(\mathrm{P}<0.001)$ and a small, but significant decrease in copy number for NDRG2 $(\mathrm{P}<0.001)$. For NDRG4, no change in copy number was observed using the TCGA data (Fig. 2B).

\subsubsection{Epigenetic changes}

The presence of multiple CpG islands in the promoter region of NDRG1, NDRG2 and NDRG4 renders these genes suitable for regulation by DNA methylation during carcinogenesis. In line, primary and metastatic colon cancer cell lines (e.g. SW480 and SW620) show minimal NDRG1 CpG island methylation [53] and a number of GI-cancer cell lines and colon cancer tissues show variable NDRG2 promoter hypermethylation at several CpG sites, with levels ranging between 27 to $100 \%$ [45,57-60]. Promoter hypermethylation of NDRG2 corresponds well with reduced NDRG2 expression in CRC [45,57-60]. In fact, 84$100 \%$ of the hypermethylated tissues lack NDRG2 mRNA expression and immunoreactivity [57-59]. The differential methylation pattern could be explained by the presence of several transcription start sites (TSS) with distinct promoters having CpG islands, primarily located in exon 1 and 2 of the NDRG2 gene [50], and the use of different primer sequences to analyze the methylation status of the NDRG2 promoter [45,50,58,59,61]. Similarly, for NDRG4 promoter methylation, we showed that a primer pair located in the region with dense promoter methylation (more 5' relative to TSS) yielded a sensitivity of $86 \%$ for CRC detection, which decreased to $71 \%$ when using a second primer pair located in a region with less dense promoter methylation (more 3' relative to TSS) [12].

The epigenetic regulation of NDRG1, NDRG2 and NDRG4 during CRC has been further confirmed by the reduced promoter methylation and consequential increase in NDRG1, NDRG2 and NDRG4 expression in GI-cancer cell lines treated with the DNA methyltransferase inhibitor 5-aza-2'-deoxycytine (DAC). Moreover, treatment with the histone deacetylase inhibitor trichostatin A (TSA) further enhanced the expression of NDRG1, NDRG2 and NDRG4, suggesting that their expression is regulated by histone acetylation and promoter methylation [12,23,45,50,53,58-61]. In contrast, the mechanism of epigenetic silencing of NDRG3 expression has, to our knowledge, not been described in literature.

TCGA methylation data for 272 colorectal cancer tissues and 37 colonic tissues from healthy controls (Fig. 2C), confirm the minimal CpG island methylation of NDRG1, as only four out of ten Infinium 450k probes within $2 \mathrm{~kb}$ either side of the TSS of NDRG1 showed a significant difference in methylation between tumor and normal samples (Wilcoxon rank sum test, $\mathrm{P}<0.001$ ). In addition, TCGA data show a variable degree of methylation at different $\mathrm{CpG}$ sites in NDRG2, with $1 / 14$ and $7 / 14$ of the analyzed CpGs, respectively, having a significantly reduced or increased methylation status in CRC (Wilcoxon rank sum test, $\mathrm{P}<0.001$ ). Further, in tumor tissue of CRC patients, the NDRG4 gene is characterized by the highly increased methylation of $13 / 15$ promoter $\mathrm{CpG}$ sites compared to healthy controls (Wilcoxon rank sum test, $\mathrm{P}<0.001$ ). Finally, TCGA-derived methylation data show a statistically significant increase in methylation for four out of seven promoter CpGs of the NDRG3 gene when comparing CRC to normal samples (Wilcoxon rank sum test, $\mathrm{P}<0.001$ ). The observed methylation is however, unlikely to have any biological effect as NDRG3 expression between tumor and normal samples is not changed (Fig. 2A).

In addition, chromatin remodeling and miRNAs can also influence the gene expression of NDRG1 and NDRG2 in the development and progression of CRC. For instance, the chromatin structure of NDRG1 in 

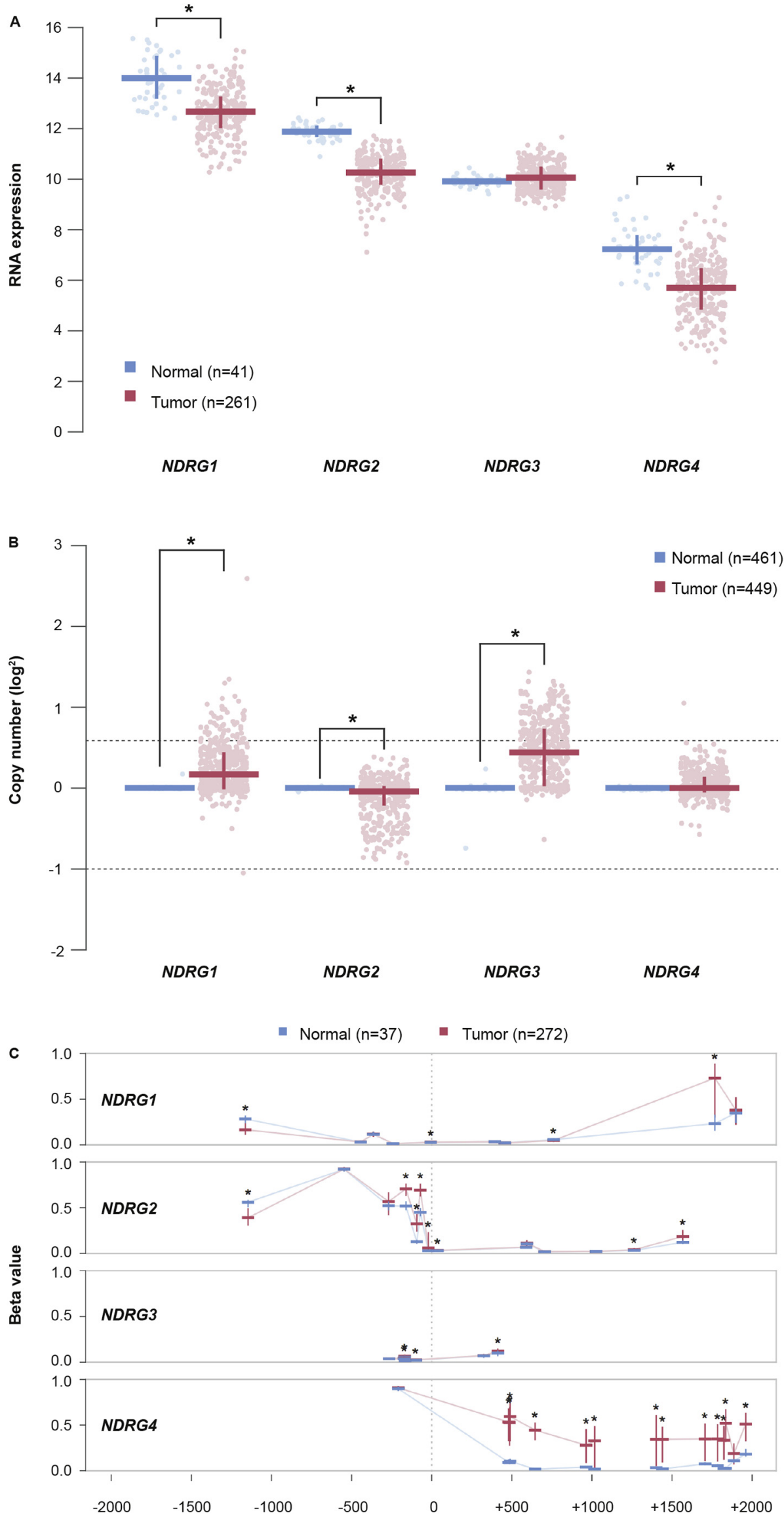

Fig. 2. Differences in NDRGs between normal and tumor tissue from CRC patients as shown by TCGA data. A. TCGA-derived RNA expression analysis reveals, in agreement with the literature, the reduced expression of NDRG1, 2 and 4 in tumor tissue $(\mathrm{n}=261)$ compared to normal tissue $(\mathrm{n}=41)$. NDRG3 expression on the other hand is very slightly, but not significantly increased. Statistical test; Wilcoxon rank sum test. * Indicate $\mathrm{P}<0.001 \mathrm{~B}$. TCGA copy number data show that, compared to normal samples $(n=461)$, tumor tissues $(n=449)$ have a significantly increased copy number of NDRG1 and NDRG3, a significantly reduced copy number of $N D R G 2$, and an unaltered level of NDRG4. The dotted lines represent the copy number ratios with the upper one indicating an extra copy (3/2) and the lower representing loss of a copy (1/2). Statistical test; Wilcoxon rank sum test. * Indicate $\mathrm{P}<0.001 \mathrm{C}$. The CpG methylation status of TCGA samples indicates that each $N D R G$ is more frequently methylated in tumor tissues $(\mathrm{n}=272)$ compared to normal tissues $(n=37)$. In contrast to the few $\mathrm{CpGs}$ that are methylated in the NDRG1 (4/10) and NDRG3 (4/7) gene, methylation occurs most frequently in the NDRG4 (13/15) and NDRG2 (8/14) gene in CRC tissues. Statistical test; Wilcoxon rank sum test. * Indicate $\mathrm{P}<0.001$. 
SW480 cells has been described to be more accessible for the Polymerase II enzyme, suggesting a more active transcription of NDRG1 and a higher level of NDRG1 expression in SW480 compared to SW620 cells $[23,53]$. According to Feng et al. NDRG2 represents a direct target of microRNA-650 (miR-650): increased miR-650 levels diminish $N D R G 2$ expression in colon cancer cells, which is reversible by treatment with anti-miR-650 [45].

\section{The biomarker potential of the NDRG members}

Due to their differential expression in various conditions, numerous studies have investigated the correlation between the level of NDRG1, NDRG2 and NDRG4, and various clinico-pathological variables and studied their potential as diagnostic, prognostic or predictive biomarkers for CRC (Suppl. table 1).

\subsection{Diagnostic biomarkers}

NDRG4 is the only NDRG-relative that has been studied in diagnostic biomarker research owing to its distinct level of DNA (promoter) methylation in healthy people versus CRC patients.

In 2009, we reported that the frequency of NDRG4 DNA promoter methylation significantly increased from normal $(0-16 \%)$ to adenoma (61-63\%) to carcinoma tissue (84-86\%) [12]. Several independent groups (Suppl. Table 1) confirmed that NDRG4 DNA promoter methylation could sensitively discriminate CRC tissues (68-76\%), and advanced adenomas (81.0-89.0\%) from normal mucosa, with a specificity of 91.7-97.0\% [8,13,62,63]. Although most studies conclude that the frequency of NDRG4 DNA promoter methylation in tissues is not associated with any clinicopathological variable, Zou et al. and Park et al. described that the NDRG4 promoter methylation significantly increased with age during carcinogenesis $(\mathrm{P}<0.001)$, and that methylation tends to be higher in patients aged $\geq 60(P=0.077)[62,63]$. Besides, the frequency of NDRG4 promoter methylation has been shown to be higher in (i) right versus left colon tumors ( $\mathrm{P}<0.001-0.290)$, (ii) stage III and IV CRC compared to stage I and II CRCs and (iii) in females with FIT-negative versus females with FIT-positive cancers $(\mathrm{P}=0.003)$ $[62,64]$.

To investigate the utility of NDRG4 DNA promoter methylation as a noninvasive biomarker for the detection of CRC, several studies examined the frequency of NDRG4 DNA promoter methylation in fecal DNA of CRC patients and healthy controls. We and numerous independent groups revealed that NDRG4 DNA promoter methylation in fecal DNA, as a single marker has a sensitivity for the detection of CRC patients between $29-88 \%$ at a high specificity (89-100\%) [7-15].

Notwithstanding the performance of NDRG4 DNA promoter methylation as a single stool marker, several studies combined NDRG4 with other markers to investigate if this would enhance the sensitivity and specificity for CRC detection. The multi-target stool DNA test that combines several methylated markers (e.g. NDRG4, Vimentin, BMP3, TFPI2), with mutant KRAS and/or fecal hemoglobin, can detect 85.0$87.0 \%$ of CRCs, $42.4-92.0 \%$ of CRC + adenomas + dysplasia, and $54.0 \%$ of adenomas $\geq 1 \mathrm{~cm}$ at $87.0-94.0 \%$ specificity [7,65-68]. Interestingly, the combination of only NDRG4 and BMP3 DNA promoter methylation further enhanced the sensitivity to $100 \%$ at $89 \%$ specificity [10]. Consequently, Exact Sciences (Madison, USA) developed the Cologuard $^{\circledR}$ test that combines a marker panel of methylated NDRG4 and $B M P 3$, mutant KRAS, and a quantitative detection of fecal hemoglobin for an even more accurate detection of CRC. The accurate performance of the Cologuard ${ }^{\circledR}$ for CRC screening was highlighted by a number of studies and further established by Imperiale et al. in a large multicenter trial including over 10.000 participants at average risk for CRC. Data from these studies revealed that the Cologuard ${ }^{\circledR}$ has a sensitivity of $92.3-100 \%$, for the detection of CRC patients and of $42.4 \%$ for the detection of advanced precursor lesions, at a specificity of 86.6-91.0\%, irrespective of stage, size and tumor location [14,16,66,69]. Finally, similar as observed for methylated NDRG4 alone, the sensitivity of both the stool DNA test and Cologuard ${ }^{\circledR}$ typically increased with adenoma and CRC size [7,65,69].

At last, it has been described that NDRG4 DNA promoter methylation in plasma has a sensitivity of $27.0 \%-54.8 \%$ to detect CRC patients at a specificity of $78.1-95.0 \%[13,70]$ and that NDRG4 DNA promoter methylation in urine samples also sensitively $(72.6 \%)$ detects CRC, yet at a slightly reduced specificity (85.0\%) [13].

\subsection{Prognostic biomarkers}

As described above, the mRNA and protein levels of NDRG1 in tumor tissue significantly differ from the levels observed in normal gut tissue. All studies agree that the level of NDRG1 mRNA or protein expression is not influenced by age and gender, nor with the localization of the primary tumor (Suppl. Table 1). Nevertheless, except for three studies [38-40], all studies observed that NDRG1 expression is inversely correlated with the degree of lymph node and distant metastasis and advanced TNM stage, while being positively associated with welldifferentiated (less aggressive) tumors. Moreover, these studies found $N D R G 1$ to be an independent, favorable prognostic factor for CRC. In fact, when not differentiating between cancer stages, the overall survival (OS) rate for CRC patients with NDRG1 expression was remarkably higher compared to those with reduced NDRG1 levels $(P=0.000-0.148)[40,42,43,54]$. When looking at separate stages, the survival rate of stage II and IV patients with preserved NDRG1 mRNA expression in the tumor was significantly better compared to patients with reduced $N D R G 1$ tumor levels $(\mathrm{P}=0.0005)$ [40]. In addition, the disease free survival (DFS) and progression free survival (PFS) rate were 1.3-2.0 fold higher for the patients with preserved NDRG1 protein expression in the tumor compared to the ones having reduced NDRG1 tumor levels $(P=0.003-0.004)[42,54]$, suggesting that NDRG1 is an independent prognostic factor for both recurrence and overall survival. Interestingly, Koshiji et al. reported that NDRG1 expression significantly correlated with Duke's stage in Japanese $(P=0.036)$, and Caucasians $(P=0.0063)$, but not in African Americans $(P=0.880)$. In addition, a worse survival rate was observed in US African American patients only $(\mathrm{P}=0.035)$, suggesting that the ethnic background affects the level of NDRG1 expression and its correlation with clinico-pathological variables and disease outcome [38].

While different studies investigated the correlation of NDRG2 expression with clinico-pathological variables, only two further explored the prognostic potential of NDRG2 [44,58]. NDRG2 mRNA and protein levels have been described to positively correlate with the differentiation state of the tumor $(\mathrm{P}<0.0001-0.450)$ and inversely relate to TNM staging $(\mathrm{P}<0.001-0.772)$ and lymph node metastasis $(\mathrm{P}<0.001$ 0.214). In addition, Hong et al. reported a higher level of NDRG2 promoter methylation in the proximal compared to the distal colon $(P=0.022)$ and in advanced T-stage tumors $(P=0.039)$ [58]. No significant association was observed between NDRG2 expression and age, gender or distant metastasis. However, CRC patients with tumors characterized by high levels of NDRG2 promoter methylation or reduced expression of NDRG2 have a worse OS rate $(\mathrm{P}=0.003-0.145)$ as well as a shorter DFS/higher recurrence risk $(\mathrm{P}=0.002-0.216)$ compared to those having tumors with preserved NDRG2 expression or low levels of NDRG2 promoter methylation [44,58]. Consequently, NDRG2 also has the potential of being a prognostic biomarker for CRC.

While we have to be cautious with the conclusions drawn in the study by Chu et al. regarding the prognostic potential of NDRG4 [34], as these were based on the inaccurate detection of NDRG4 with a nonspecific anti-NDRG4 antibody [32], a second study by this group (Zheng et al.) shows similar results using differential mRNA expression analysis [51]. The OS and DSF time of patients with NDRG4 mRNA positive tumors was significantly improved compared to the group with NDRG4 negative tumors ( $\mathrm{P}<0.001$ for both) [51]. Furthermore, NDRG4 expression was not affected by age, gender or tumor location, 
whereas it was significantly positively correlated with tumor differentiation $(P=0.001)$, and inversely related to distant $(P=0.001)$ and lymph node metastasis $(\mathrm{P}=0.004)$ and TNM staging $(\mathrm{P}=0.001)$ [51].

\subsection{Predictive biomarkers}

Only a very limited number of studies have investigated the predictive value of NDRG1 in CRC cell lines and CRC patients [43,54]. Wangpu et al. observed an increased sensitivity of NDRG1-overexpressing HT29 and HCT116 cells to increasing concentrations of 5fluorouracil $(P<0.001-0.010)$ [71]. Ma et al. described that SW480 cells are more prone to Irinotecan treatment upon knockdown of $N D R G 1$, with a significantly lower $\mathrm{IC}_{50}$ value compared to control transfected cells $(P<0.050)$ [54]. Similarly, a high level of NDRG1 expression tends to cause resistance to Irinotecan-based therapy, as patients who developed a recurrence while having high NDRG1 tumor levels, received Irinotecan-based therapy only for 6.8 months, whereas those with a low tumor level of NDRG1 remained on this therapy for 9.3 months $(P=0.070)$ [43]. No studies have explored the predictive biomarker value for either NDRG2, 3 or 4 .

\section{Functional roles and pathways involving the NDRGs}

It has been recognized that the NDRG family mainly functions in proliferation and differentiation in multiple types of cells/cancers (for reviews we refer to [72-75]). The limited number of studies that suggest a regulatory function for NDRG3 and NDRG4 in proliferation and differentiation are summarized by Yang et al. [76] and Melotte et al. [2]. In this review, we further elaborate on the mechanisms that have consequences for intestinal functions in normal and cancerous conditions.

\subsection{Cell survival: proliferation versus p53/apoptosis}

Kim et al. observed that NDRG1 is localized in the centrosome of CRC cells as a microtubule-associated protein and participates in the cell cycle as a mitotic checkpoint [77]. Furthermore, in p53-deficient tumor cell lines (incl. the CRC cell lines DLD-1 and HCT116-p53/- ), NDRG1 was shown to inhibit polyploidy development and to increase the number of cells in cell cycle arrest [77]. Hence, NDRG1 can protect against uncontrolled proliferation. Stein et al. further reported that NDRG1 expression was induced by DNA damage through a mechanism involving p53 in these CRC cell lines [78], which could explain the increased level of NDRG1 in response to hypoxia, as hypoxia induces p53 accumulation and stabilization [78]. Later, Zhang et al confirmed that another type of stress, nutrient/polyamine depletion, can stabilize p53 and by this means enhance NDRG1 expression in normal intestinal epithelial (IEC-6) and CRC cells (HCT116-p53/-) [79]. In both studies, NDRG1 expression was not sufficient to induce apoptosis, but it did inhibit DNA synthesis and proliferation [78,79]. In contrast, Ambrosini et al. revealed that the shRNA-mediated silencing of NDRG1 in HCT116 cells led to increased levels of the pro-apoptotic Bim protein [80], similar as reported by Ma et al. [54]. When NDRG1 was reintroduced in the cells, it suppressed Bim stability by mediating its binding to the proteasome, thereby repressing the apoptotic machinery [80]. Thus, NDRG1 likely functions in controlling and repressing proliferation, but is not sufficient to induce apoptosis in intestinal cells.

Several studies suggest the anti-proliferative effects of NDRG2 in CRC cells (e.g. SW48, SW480, SW620, DLD-1, HCT116). Kim et al. first showed that NDRG2 suppresses AP-1, which results in the down-regulation of cyclin D1, the subsequent cell cycle arrest in the G1/S phase and a concomitant reduction in cell proliferation [46,81]. Further, Golestan et al. and Hong et al. observed that the overexpression of NDRG2 in SW48, DLD-1 and RKO cells reduces cell viability and inhibits cell proliferation, suggesting that NDRG2 might have tumor suppressing roles [58,82].

Likewise, but not restricted to CRC cells, Park et al. observed that hypoxia induced the accumulation of NDRG3 and the subsequent activation of the Raf-ERK pathway, which was associated with increased anti-apoptotic effects [83].

Previously, we observed that NDRG4 overexpression in CRC cells suppressed colony formation and the proliferative capabilities of these cells [12], suggesting a tumor suppressor role in CRC. In addition, Chu et al. proposed further evidence for the anti-proliferative effects of NDRG4 during CRC, as they described how NDRG4 overexpression in the metastatic SW620 CRC cell line considerably decreased PI3K-AKT activation by reducing AKT phosphorylation [12,34]. No other studies examined potential pathways of NDRG4 in CRC.

\subsection{Metastasis/invasion/epithelial-mesenchymal transition}

As described-above, metastatic CRC tissue and cell lines express reduced levels of endogenous NDRG1. In view of this, several studies have shown that NDRG1 is able to suppress metastasis and invasion. Guan et al. found that NDRG1 overexpression in the metastatic CRC cell line SW620 inhibits invasion [23]. Moreover, even after treatment with TGF- $\beta$ [71,84], NDRG1 suppresses the epithelial-mesenchymal transition (EMT) in colon cancer cells (e.g. HCT116, HT29) by preventing stress fiber formation and cell motility through suppression of the ROCK1/pMLC2 pathway and by stimulating the membrane expression of E-cadherin and $\beta$-catenin [85]. More precisely, NDRG1 induced three mechanisms to maintain $\beta$-catenin at the cell membrane by: (i) inhibiting the phosphorylation of $\beta$-catenin through up-regulating the GSK-3 $\beta$-binding protein, frequently rearranged in advanced T-cell lymphoma 1 (FRAT-1), (ii) preventing the nuclear localization of $\beta$ catenin via down-regulation of p21 activated kinase 4 (PAK-4) distribution in the nucleus $[71,86]$ and (iii) ensuring the ubiquitylation and subsequent degradation of caveolin-1 (cav-1) [87]. Similarly, NDRG1 prevents the EMT and metastatic/invading capabilities of CRC cells by inhibiting NF- $\mathrm{kB}$ (a key player in oncogenesis) and Cav-1: as NDRG1 knockdown increased the levels of NF- $\mathrm{kB}$, Cav-1 and the mesenchymal markers Vimentin and Snail, while decreasing the expression of the epithelial marker E-cadherin [54,87]. Finally, NDRG1 prevents the recruitment of a key proto-oncogene: cellular Src to EGFR, thereby inhibiting Src phosphorylation (Tyr416) and its subsequent activation, thus inhibiting metastasis [88]. In addition, overexpression of NDRG1 in HT29 cells reduced cell migration, focal adhesions, and cell collagen adhesion through a diminished activation of the important oncogenic FAK/paxillin pathway [89].

Similar as for NDRG1 [84], Shen et al. investigated the effect of NDRG2 on TGF- $\beta$-treated HT29 cells [90]. TGF- $\beta$, which has tumor suppressor activities in early CRC stages but oncogenic actions in late stages, enhanced the EMT through down-regulation of E-cadherin and up-regulation of Vimentin. Importantly, overexpression of NDRG2 could reverse this TGF- $\beta$-induced EMT transition whereby cells restored their epithelial morphology, while NDRG2 knockdown further enhanced the TGF- $\beta$-induced EMT [90]. In addition, NDRG2 exerts its suppressive effects on invasion and migration in DLD-1, RKO and SW48 cells probably through inhibition of matrix metalloprotease (MMP)-9 activity, which is involved in tumor invasion via degradation of extracellular matrix proteins and activation of TGF- $\beta$ [58,82].

In accordance with the effects of NDRG1 on $\beta$-catenin, NDRG2 has 
been shown to (in-) directly reduce $\beta$-catenin and its major downstream T-cell factor/lymphoid enhancer factor (TCF/LEF) signaling pathway in various CRC cell lines (e.g. HCT116 and SW620 cells). Hwang et al. revealed the direct association of the NDRG2 protein, with $\beta$-catenin and the subsequent inhibition of TCF/LEF signaling in SW620 cells [91]. On the other hand, NDRG2 can activate GSK-3 $\beta$, which in turn induces the degradation of $\beta$-catenin and subsequently suppresses $C$ $M y c$ [92,93]. This NDRG2-mediated activation of GSK-3 $\beta$ also induced degradation of Snail, followed by de-repression of E-cadherin [46,94]. Together, these effects led to increased levels of E-cadherin and $\beta$-catenin at the plasma membrane, thereby inhibiting the EMT. Lastly, Kim et al. determined the prenylated Rab acceptor 1 (PRA1), a protein involved in vesicle trafficking and protein transport, to be a binding partner for NDRG2 [95]. They synergistically inhibit GSK-3 $\beta$ phosphorylation, thereby preventing nuclear translocation of $\beta$-catenin. Interestingly, NDRG1, NDRG2, and NDRG3 all suppress cell growth and TCF promotor activity by their synergistical interaction with PRA1 [95].

We previously described that NDRG4 inhibits metastasis, by reducing the invading capacities of NDRG4-overexpressing HCT116 cells [12], most likely by targeting some of the above-mentioned pathways. Indeed, Chu et al. observed that NDRG4 suppresses PI3K-AKT activity, since NDRG4 overexpression in SW620 cells reduced AKT phosphorylation [34]. As AKT is a well-known upstream inhibitor of GSK-3 $\beta$, we postulate that upon NDRG4 expression, the inhibition of GSK-3 $\beta$ is abolished through down-regulation of AKT, thereby leading to degradation of $\beta$-catenin and $C-M y c$ repression, resulting in the inhibition of the EMT. Although in the heart, Xing et al. observed a similar mechanism during ischemia-reperfusion injury, where the TNF- $\alpha$-dependent NF- $\mathrm{kB}$ activation increased myocardial expression of NDRG4, which is associated with a concomitant decrease in AKT phosphorylation, promoting apoptosis [96].

A schematic overview of the above-described pathways influenced by NDRG1, NDRG2, NDRG3 and NDRG4 during cell survival and the EMT are shown in Fig. 3A and B, respectively.

\section{Conclusion}

Overall, we can deduce that the NDRGs have a variable expression pattern, both in the embryonic and adult gut. NDRG1 expression highly exceeds the expression of NDRG2, NDRG3 and NDRG4 in the fetal gut. Although one might argue this is possibly caused by a lower expression or less specific cell types expressing $N D R G 2,3$ and 4 in total gut biopsies, we observe a similar pattern in the matured GI-tract, suggesting that the intestinal epithelium is rich in NDRG1. NDRG2, 3 and 4 are however, up-regulated in ENCCs during embryonic stages, but display a distinct pattern in the mature gut: NDRG2 expression in epithelial cells, an unknown pattern for NDRG3 and the ENS-specific expression of NDRG4. Hence, further studies should be performed to resolve the fundamental question whether expression of NDRG2 and 3 is retained in ENCCs during intestinal maturation and appears in the ENS of the adult gut or rather moves towards the cells of the epithelial layer during gut development.

Furthermore, the above-described knowledge regarding the developmental expression of NDRG2, NDRG3 and NDRG4 in ENCCs, and the adult expression of NDRG4 specifically in the ENS, led to the question whether the NDRGs, via the ENS, contribute to the development and progression of CRC. While it is well-known that the ENS is pivotal to maintain gut homeostasis, there is little evidence linking the ENS with CRC. In our recent review by Rademakers et al. we summarized the preliminary evidence linking the ENS with CRC and hypothesized that enteric neurons communicate with the intestinal epithelium via the production and secretion of neurotrophic factors through vesicle transport [97]. Interestingly, NDRG4 has been shown to regulate some important SNARE-proteins of the vesicle trafficking machinery as (i) its interaction with BVES regulates docking and cargo delivery of VAMP-3 vesicles, and (ii) its knockdown is associated with a sharp reduction in the level of SNAP-25. Moreover, we here review the interaction of NDRG2 (NDRG1 and NDRG3) with PRA1, a protein involved in exocytosis by binding to the SNARE-receptor. Finally, NDRG3 interacts with CPLX1, which regulates synaptic vesicle exocytosis by allowing SNAREs (like SNAP25) to release neurotransmitters only upon arrival of an action potential [98]. Thus we hypothesize that the NDRGs in the ENS can affect the intestinal epithelium through regulation of vesicle transport.

Besides, we acknowledge the significance of the differential expression of NDRG1, NDRG2, NDRG3 and NDRG4 in normal and cancerous intestinal tissues, which is, for NDRG2 and NDRG4 mainly caused by DNA promoter hypermethylation. Additionally, the increased expression of NDRG1 and NDRG2 during intestinal epithelial cell differentiation and reduced expression of NDRG1, 2 and 4 in the cancerous gut and their metastasis, suggest a possible role for these family members as tumor/metastasis suppressor genes.

Based on their differential expression patterns, the NDRGs are described as potential diagnostic (NDRG4), prognostic (NDRG1, 2 and 4) and predictive (NDRG1) biomarkers for CRC. Indeed, the highly upregulated level of NDRG4 DNA promoter methylation in fecal DNA represents a non-invasive early detection marker for CRC that has been successfully implemented in clinical use in the USA, as part of the Cologuard $^{\circledR}$ test. While the significantly reduced expression of NDRG1, 2 and 4 in tumor tissues of CRC patients can define the prognostic value for CRC (i.e. worse OS and DSF), it is important to realize that these levels may vary when using different antibodies, varying experimental techniques, and even in population groups with a diverse ethnic background. Furthermore, the potential predictive value of NDRG1 for response to Irinotecan or 5-Fluorouracil treatment in CRC needs more in-depth investigation before it can be applied in the clinic.

Finally, we reiterate that NDRG1, 2 and 4 exert pleiotropic effects, mostly inhibiting key hallmarks of carcinogenesis (e.g. proliferation, differentiation, metastasis) during CRC. Indeed, NDRG1 and NDRG2 have been shown to alter proliferative and apoptotic pathways (e.g. cell cycle and EGFR signaling) and the epithelial-mesenchymal transition. Limited data on the functional role of NDRG4 in the gut also suggest tumor suppressor activities for NDRG4 during CRC, whereas no mechanism of action for NDRG3 in colorectal carcinogenesis has been defined. More insight into the pathways in which NDRG3 and NDRG4 are involved, can be drawn from described effects in other (cancerous) tissue types and suggests that NDRG3 affects the apoptotic machinery [83] and that NDRG4 is able to modulate similar targets as defined for NDRG1 and NDRG2, in apoptotic, proliferative (e.g. p53, cyclin D1) [99-101] and EMT-signaling pathways (e.g. WNT/ $\beta$-catenin, TGF- $\beta$, EGFR-downstream targets) [34,102,103]. Nevertheless, it is important to keep in mind that despite the involvement of NDRGs in similar pathways, their effects may vary (i.e. tumor suppressor versus oncogene) depending on the tissue type.

\section{Funding}

This work was supported by the KWF Kankerbestrijding grant (UM 2013-6075) obtained by Dr. Veerle Melotte. The Genotype-Tissue Expression (GTEx) Project was supported by the Common Fund of the Office of the Director of the National Institutes of Health, and by NCI, 
A
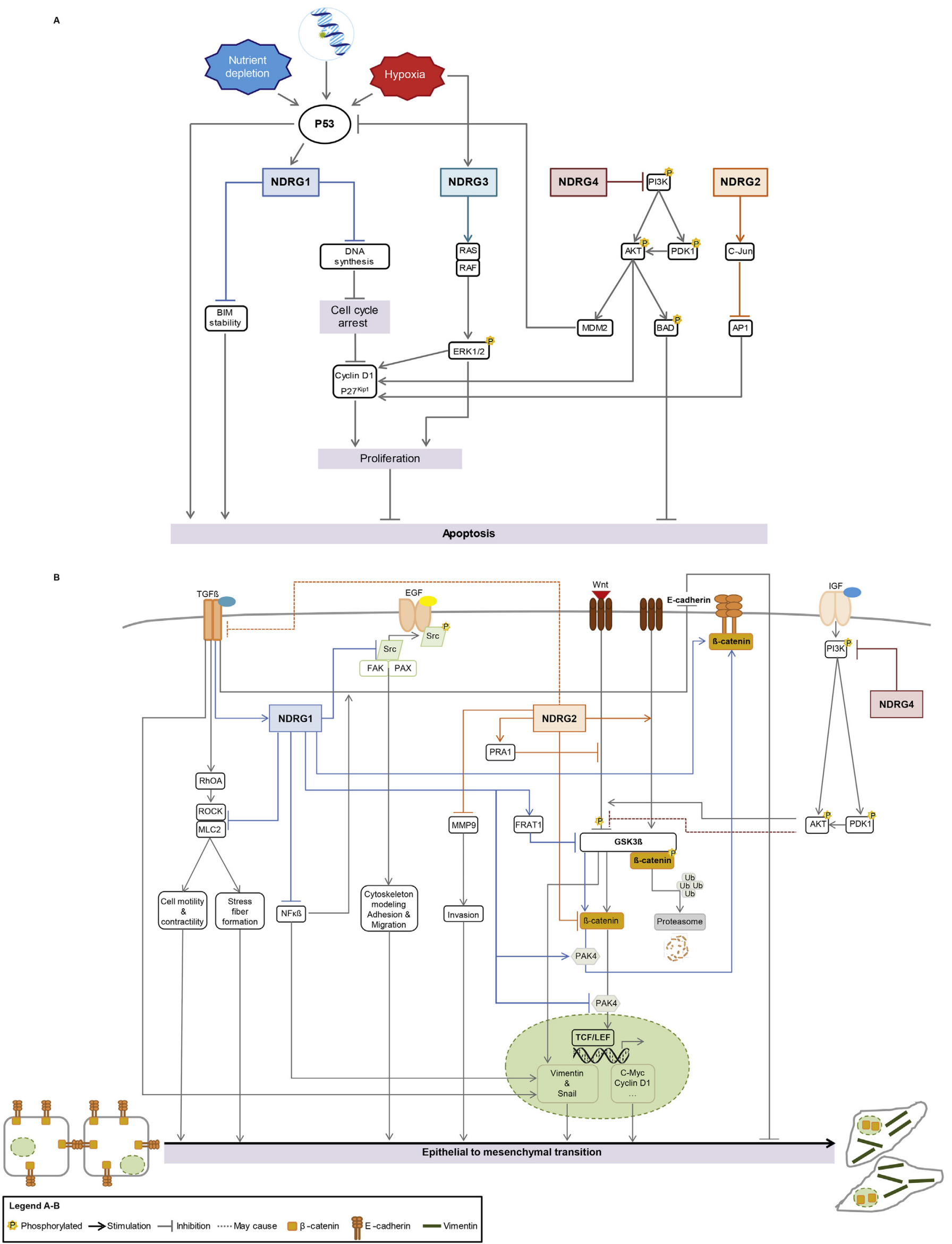


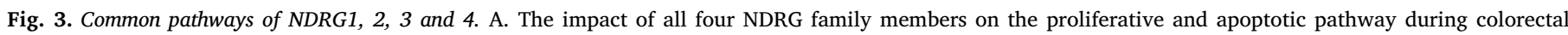

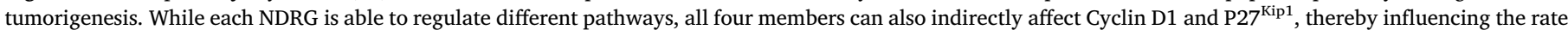

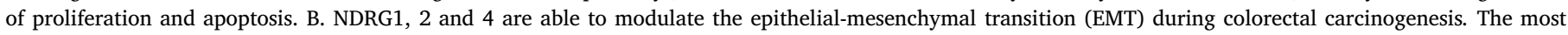

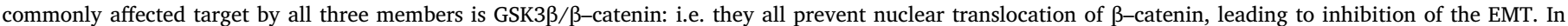

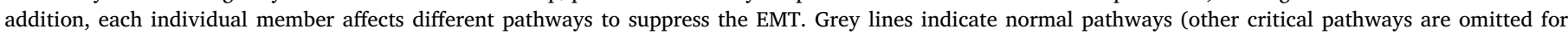

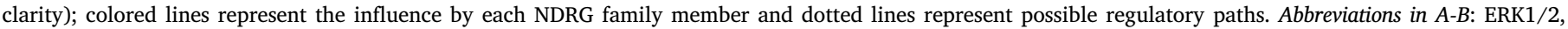

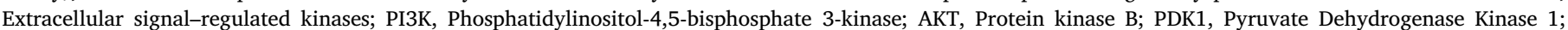

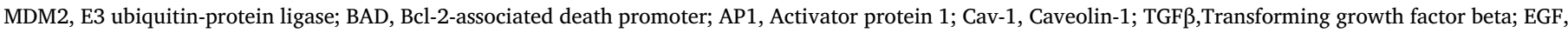

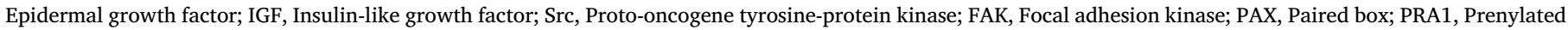

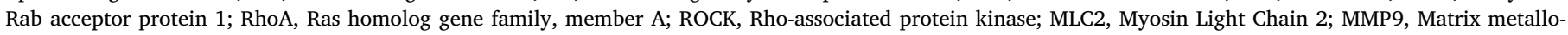

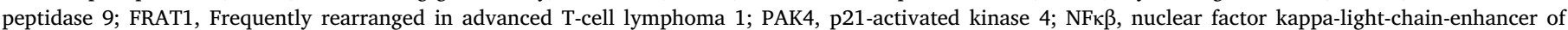
activated B cells; TFC/LEF, T-cell factor/Lymphoid enhancer factor.

NHGRI, NHLBI, NIDA, NIMH, and NINDS. The human embryonic and fetal material was provided by the Joint MRC/Wellcome Trust grant \#099175/Z/12/Z Human Developmental Biology Resource (http:// hdbr.org).

\section{Availability of data and materials}

The results shown in the section: "Differential expression levels during intestinal carcinogenesis" are in part based upon data generated by the TCGA Research Network: http://cancergenome.nih.gov/. The data used for the analyses described in the section: "Expression pattern of the NDRGs in the developing and adult gut" were obtained from: [https://gtexportal.org/home/] the GTEx Portal on 06/19/2017. The human embryonic and fetal material was provided by the Joint MRC/ Wellcome Trust grant \#099175/Z/12/Z Human Developmental Biology Resource (http://hdbr.org).

\section{Author contributions}

NV and SS performed the literature search; NV and VM designed the study; EB and AK analyzed the data derived from databases (EB, GTEx and mouse embryonic data; AK, TCGA data); CJM and NT assembled all data of the GTEx project; NV, EB, AK, RMWH, MvE and VM contributed towards data interpretation; NV, SS, EB and AK generated the figures; $\mathrm{NV}$, SS and VM wrote the paper; EB, AK, CJM, NT, RMWH and MvE provided critical revisions of the manuscript.

\section{Competing interests}

The authors declare that they have no competing interests.

\section{Appendix A. Supplementary data}

Supplementary data to this article can be found online at https:// doi.org/10.1016/j.bbagen.2018.07.004.

\section{References}

[1] A. Shimono, T. Okuda, H. Kondoh, N-myc-dependent repression of ndr1, a gene identified by direct subtraction of whole mouse embryo cDNAs between wild type and N-myc mutant, Mech. Dev. 83 (1999) 39-52.

[2] V. Melotte, X. Qu, M. Ongenaert, W. van Criekinge, A.P. de Bruine, H.S. Baldwin, M. van Engeland, The N-myc downstream regulated gene (NDRG) family: diverse functions, multiple applications, FASEB J. 24 (2010) 4153-4166.

[3] A. Bhaduri, L. Krishnaswamy, G.R. Ullal, M.M. Panicker, R. Sowdhamini, Fold prediction and comparative modeling of Bdm1: a probable alpha/beta hydrolase associated with hot water epilepsy, J. Mol. Model. 9 (2003) 3-8.

[4] E. Shaw, L.A. McCue, C.E. Lawrence, J.S. Dordick, Identification of a novel class in the alpha/beta hydrolase fold superfamily: the N-myc differentiation-related proteins, Proteins 47 (2002) 163-168.

[5] X. Qu, Y. Zhai, H. Wei, C. Zhang, G. Xing, Y. Yu, F. He, Characterization and expression of three novel differentiation-related genes belong to the human NDRG gene family, Mol. Cell. Biochem. 229 (2002) 35-44.

[6] R.H. Zhou, K. Kokame, Y. Tsukamoto, C. Yutani, H. Kato, T. Miyata, Characterization of the human NDRG gene family: a newly identified member, NDRG4, is specifically expressed in brain and heart, Genomics 73 (2001) 86-97.

[7] D.A. Ahlquist, H. Zou, M. Domanico, D.W. Mahoney, T.C. Yab, W.R. Taylor,
M.L. Butz, S.N. Thibodeau, L. Rabeneck, L.F. Paszat, K.W. Kinzler, B. Vogelstein, N.C. Bjerregaard, S. Laurberg, H.T. Sorensen, B.M. Berger, G.P. Lidgard, Nextgeneration stool DNA test accurately detects colorectal cancer and large adenomas, Gastroenterology 142 (2012) 248-256 quiz e225-246.

[8] D.H. Johnson, W.R. Taylor, M.M. Aboelsoud, P.H. Foote, T.C. Yab, X.M. Cao, T.C. Smyrk, E.V. Loftus, D.W. Mahoney, D.A. Ahlquist, J.B. Kisiel, DNA Methylation and Mutation of Small Colonic Neoplasms in Ulcerative Colitis and Crohn's Colitis: Implications for Surveillance, Inflamm. Bowel Dis. 22 (2016) 1559-1567.

[9] J.B. Kisiel, W.R. Taylor, H. Allawi, T.C. Yab, J.A. Simonson, M.E. Devens, K.L. Lowrie, L.A. Boardman, T.C. Smyrk, G.P. Lidgard, D.W. Mahoney, D.A. Ahlquist, Detection of colorectal cancer and polyps in patients with inflammatory bowel disease by novel methylated stool DNA markers, Gastroenterology (1) (2014) S440-S441.

[10] J.B. Kisiel, T.C. Yab, F.T.N. Hussain, W.R. Taylor, M.M. Garrity-Park, W.J. Sandborn, E.V. Loftus, B.G. Wolff, T.C. Smyrk, S.H. Itzkowitz, D.T. Rubin, H. Zou, D.W. Mahoney, D.A. Ahlquist, Stool DNA testing for the detection of colorectal neoplasia in patients with inflammatory bowel disease, Aliment. Pharmacol. Ther. 37 (2013) 546-554.

[11] H.N. Lu, S.L. Huang, X. Zhang, D.P. Wang, X.S. Zhang, X.G. Yuan, Q.B. Zhang, Z.G. Huang, DNA methylation analysis of SFRP2, GATA4/5, NDRG4 and VIM for the detection of colorectal cancer in fecal DNA, Oncol. Lett. 8 (2014) 1751-1756.

[12] V. Melotte, M.H. Lentjes, S.M. van den Bosch, D.M. Hellebrekers, J.P. de Hoon, K.A. Wouters, K.L. Daenen, I.E. Partouns-Hendriks, F. Stessels, J. Louwagie, K.M. Smits, M.P. Weijenberg, S. Sanduleanu, C.A. Khalid-de Bakker, F.A. Oort, G.A. Meijer, D.M. Jonkers, J.G. Herman, A.P. de Bruine, M. van Engeland, N-Myc downstream-regulated gene 4 (NDRG4): a candidate tumor suppressor gene and potential biomarker for colorectal cancer, J. Natl. Cancer Inst. 101 (2009) 916-927.

[13] W. Xiao, H. Zhao, W. Dong, Q. Li, J. Zhu, G. Li, S. Zhang, M. Ye, Quantitative detection of methylated NDRG4 gene as a candidate biomarker for diagnosis of colorectal cancer, Oncol. Lett. 9 (2015) 1383-1387.

[14] R.I. Heigh, T.C. Yab, W.R. Taylor, F.T.N. Hussain, T.C. Smyrk, D.W. Mahoney, M.J. Domanico, B.M. Berger, G.P. Lidgard, D.A. Ahlquist, Detection of colorectal serrated polyps by stool DNA testing: Comparison with Fecal Immunochemical Testing for occult blood (FIT), PLoS One 9 (1) (2014) no pagination.

[15] J.B. Kisiel, T.C. Yab, W.R. Taylor, D.W. Mahoney, D.A. Ahlquist, Stool methylated DNA markers decrease following colorectal cancer resection-implications for surveillance, Dig. Dis. Sci. 59 (2014) 1764-1767.

[16] T.F. Imperiale, D.F. Ransohoff, S.H. Itzkowitz, T.R. Levin, P. Lavin, G.P. Lidgard, D.A. Ahlquist, B.M. Berger, Multitarget stool DNA testing for colorectal-cancer screening, N. Engl. J. Med. 370 (2014) 1287-1297.

[17] N. Cancer Genome Atlas Research, Comprehensive genomic characterization defines human glioblastoma genes and core pathways, Nature, 455 (2008) 10611068.

[18] G.T. Consortium, The Genotype-Tissue Expression (GTEx) project, Nat. Genet. 45 (2013) 580-585.

[19] D. Schriemer, Y. Sribudiani, I.J. A, D. Natarajan, K.C. MacKenzie, M. Metzger, E. Binder, A.J. Burns, N. Thapar, R.M. Hofstra, B.J. Eggen, Regulators of gene expression in Enteric Neural Crest Cells are putative Hirschsprung disease genes, Dev. Biol. 416 (2016) 255-265.

[20] T. Okuda, H. Kondoh, Identification of new genes Ndr2 and Ndr3 which are related to Ndr1/RTP/Drg1 but show distinct tissue specificity and response to Nmyc, Biochem. Biophys. Res. Commun. 266 (1999) 208-215.

[21] T. Zhang, X. Guo, Y. Chen, Retinoic acid-activated Ndrg1a represses Wnt/betacatenin signaling to allow Xenopus pancreas, oesophagus, stomach, and duodenum specification, PLoS One, 8 (2013) e65058.

[22] M.B. Yaylaoglu, B.M. Agbemafle, T.J. Oesterreicher, M.J. Finegold, C. Thaller, S.J. Henning, Diverse patterns of cell-specific gene expression in response to glucocorticoid in the developing small intestine, Am. J. Physiol. Gastrointest. Liver Physiol. 291 (2006) G1041-G1050.

[23] R.J. Guan, H.L. Ford, Y. Fu, Y. Li, L.M. Shaw, A.B. Pardee, Drg-1 as a differentiation-related, putative metastatic suppressor gene in human colon cancer, Cancer Res. 60 (2000) 749-755.

[24] P. Lachat, P. Shaw, S. Gebhard, N. Van Belzen, P. Chaubert, F.T. Bosman, Expression of NDRG1, a differentiation-related gene, in human tissues, Histochem. Cell Biol. 118 (2002) 399-408.

[25] Z. Wang, F. Wang, W.Q. Wang, Q. Gao, W.L. Wei, Y. Yang, G.Y. Wang, Correlation of $\mathrm{N}$-myc downstream-regulated gene 1 overexpression with progressive growth of 
colorectal neoplasm, World J. Gastroenterol. 10 (2004) 550-554.

[26] N. van Belzen, W.N. Dinjens, M.P. Diesveld, N.A. Groen, A.C. van der Made, Y. Nozawa, R. Vlietstra, J. Trapman, F.T. Bosman, A novel gene which is upregulated during colon epithelial cell differentiation and down-regulated in colorectal neoplasms, Lab. Investig. 77 (1997) 85-92.

[27] X.L. Hu, X.P. Liu, Y.C. Deng, S.X. Lin, L. Wu, J. Zhang, L.F. Wang, X.B. Wang, X. Li, L. Shen, Y.Q. Zhang, L.B. Yao, Expression analysis of the NDRG2 gene in mouse embryonic and adult tissues, Cell Tissue Res. 325 (2006) 67-76.

[28] S. Boulkroun, M. Fay, M.C. Zennaro, B. Escoubet, F. Jaisser, M. Blot-Chabaud, N. Farman, N. Courtois-Coutry, Characterization of rat NDRG2 (N-Myc downstream regulated gene 2 ), a novel early mineralocorticoid-specific induced gene, J. Biol. Chem. 277 (2002) 31506-31515.

[29] M.R. Stegert, R. Tamaskovic, S.J. Bichsel, A. Hergovich, B.A. Hemmings, Regulation of NDR2 protein kinase by multi-site phosphorylation and the S100B calcium-binding protein, J. Biol. Chem. 279 (2004) 23806-23812.

[30] H. Yamamoto, K. Kokame, T. Okuda, Y. Nakajo, H. Yanamoto, T. Miyata, NDRG4 protein-deficient mice exhibit spatial learning deficits and vulnerabilities to cerebral ischemia, J. Biol. Chem. 286 (2011) 26158-26165.

[31] X.L. Hu, X.P. Liu, Y.C. Deng, S.X. Lin, L. Wu, J. Zhang, L.F. Wang, X.B. Wang, X. Li, L. Shen, Y.Q. Zhang, L.B. Yao, Expression analysis of the NDRG2 gene in mouse embryonic and adult tissues, Cell Tissue Res. 325 (2006) 67-76.

[32] N. Vaes, M. Lentjes, M.J. Gijbels, G. Rademakers, K.L. Daenen, W. Boesmans, K.A.D. Wouters, A. Geuzens, X. Qu, H.P.J. Steinbusch, B.P.F. Rutten, S.H. Baldwin, K.A. Sharkey, R.M.W. Hofstra, M. van Engeland, P. Vanden Berghe, V. Melotte, NDRG4, an early detection marker for colorectal cancer, is specifically expressed in enteric neurons, Neurogastroenterol. Motil. 29 (2017).

[33] N. Nakada, S. Hongo, T. Ohki, A. Maeda, M. Takeda, Molecular characterization of NDRG4/Bdm1 protein isoforms that are differentially regulated during rat brain development, Brain Res. Dev. Brain Res. 135 (2002) 45-53.

[34] D.K. Chu, Z.X. Zhang, Y. Zhou, Y.M. Li, S.J. Zhu, J. Zhang, Q.C. Zhao, G. Ji, W.Z. Wang, J.Y. Zheng, NDRG4, a novel candidate tumor suppressor, is a predictor of overall survival of colorectal cancer patients, Oncotarget (6) (2015) 7584-7596.

[35] X. Qu, J. Li, H.S. Baldwin, Postnatal lethality and abnormal development of foregut and spleen in Ndrg 4 mutant mice, Biochem. Biophys. Res. Commun. 470 (2016) 613-619.

[36] X. Qu, J. Li, H.S. Baldwin, Postnatal lethality and abnormal development of foregut and spleen in Ndrg4 mutant mice, Biochem. Biophys. Res. Commun. 470 (2016) 613-619.

[37] T. Kadiyska, A. Nossikoff, Stool DNA methylation assays in colorectal cancer screening, World J. Gastroenterol. 21 (2015) 10057-10061.

[38] M. Koshiji, K. Kumamoto, K. Morimura, Y. Utsumi, M. Aizawa, M. Hoshino, S. Ohki, S. Takenoshita, M. Costa, T. Commes, D. Piquemal, C.C. Harris, K.M. Tchou-Wong, Correlation of N-myc downstream-regulated gene 1 expression with clinical outcomes of colorectal cancer patients of different race/ethnicity, World J. Gastroenterol. 13 (2007) 2803-2810.

[39] Y. Song, L.Y. Lv, J. Du, L.T. Yue, L.L. Cao, Correlation of N-myc downstreamregulated gene 1 subcellular localization and lymph node metastases of colorectal neoplasms, Biochem. Biophys. Res. Commun. 439 (2013) 241-246.

[40] B. Strzelczyk, A. Szulc, R. Rzepko, A. Kitowska, J. Skokowski, A. Szutowicz, T. Pawelczyk, Identification of high-risk stage II colorectal tumors by combined analysis of the NDRG1 gene expression and the depth of tumor invasion, Ann. Surg. Oncol. 16 (2009) 1287-1294.

[41] H. Cangul, K. Salnikow, H. Yee, D. Zagzag, T. Commes, M. Costa, Enhanced overexpression of an HIF-1/hypoxia-related protein in cancer cells, Environ. Health Perspect. 110 (Suppl 5) (2002) 783-788.

[42] Z.H. Mao, J. Sun, B. Feng, J.J. Ma, L. Zang, F. Dong, D.H. Zhang, M.H. Zheng, The Metastasis Suppressor, N-myc Downregulated Gene 1 (NDRG1), Is a Prognostic Biomarker for Human Colorectal Cancer, PLoS One 8 (2013).

[43] M.A. Shah, N. Kemeny, A. Hummer, M. Drobnjak, M. Motwani, C. Cordon-Cardo, M. Gonen, G.K. Schwartz, Drg1 expression in 131 colorectal liver metastases: correlation with clinical variables and patient outcomes, Clin. Cancer Res. 11 (2005) 3296-3302.

[44] D. Chu, Z.X. Zhang, Y.M. Li, L. Wu, J. Zhang, W.Z. Wang, J.A. Zhang, Prediction of Colorectal Cancer Relapse and Prognosis by Tissue mRNA Levels of NDRG2, Mol. Cancer Ther. 10 (2011) 47-56.

[45] L. Feng, Y. Xie, H. Zhang, Y.L. Wu, Down-regulation of NDRG2 gene expression in human colorectal cancer involves promoter methylation and microRNA-650, Biochem. Biophys. Res. Commun. 406 (2011) 534-538.

[46] Y.J. Kim, S.Y. Yoon, J.T. Kim, E.Y. Song, H.G. Lee, H.J. Son, S.Y. Kim, D. Cho, I. Choi, J.H. Kim, J.W. Kim, NDRG2 expression decreases with tumor stages and regulates TCF/ beta-catenin signaling in human colon carcinoma, Carcinogenesis 30 (2009) 598-605.

[47] A. Lorentzen, R.H. Lewinsky, J. Bornholdt, L.K. Vogel, C. Mitchelmore, Expression profile of the N-myc Downstream Regulated Gene 2 (NDRG2) in human cancers with focus on breast cancer, BMC Cancer 11 (2011) no pagination.

[48] A. Lorentzen, L.K. Vogel, R.H. Lewinsky, M. Saebo, C.F. Skjelbred, S. Godiksen, G. Hoff, K.M. Tveit, I. Marie, I.M.B. Lothe, E.H. Kure, C. Mitchelmore, Expression of NDRG2 is down-regulated in high-risk adenomas and colorectal carcinoma, BMC Cancer (2007) 7.

[49] H. Shi, H.F. Jin, D.K. Chu, W.Z. Wang, J. Zhang, C.S. Chen, C.S. Xu, D.M. Fan, L.B. Yao, Suppression of N-Myc Downstream-Regulated Gene 2 Is Associated with Induction of Myc in Colorectal Cancer and Correlates Closely with Differentiation, Biol. Pharm. Bull. 32 (2009) 968-975.

[50] A. Yamamura, K. Miura, H. Karasawa, F. Motoi, Y. Mizuguchi, Y. Saiki, S. Fukushige, M. Sunamura, C. Shibata, M. Unno, A. Horii, NDRG2, suppressed expression associates with poor prognosis in pancreatic cancer, is hypermethylated in the second promoter in human gastrointestinal cancers, Biochem. Biophys. Res. Commun. 484 (2017) 138-143.

[51] J.Y. Zheng, Y.M. Li, S.J. Zhu, J.P. Li, Q.C. Zhao, G. Ji, W.Z. Wang, D.K. Chu, NDRG4 stratifies the prognostic value of body mass index in colorectal cancer, Oncotarget 7 (2016) 1311-1322.

[52] I. Nimmrich, S. Erdmann, U. Melchers, U. Finke, S. Hentsch, M.P. Moyer, I. Hoffmann, O. Muller, Seven genes that are differentially transcribed in colorectal tumor cell lines, Cancer Lett. 160 (2000) 37-43.

[53] Q. Li, H. Chen, Transcriptional silencing of N-Myc downstream-regulated gene 1 (NDRG1) in metastatic colon cancer cell line SW620, Clin. Exp. Metastasis 28 (2011) 127-135.

[54] J.L. Ma, Q.L. Gao, S. Zeng, H. Shen, Knockdown of NDRG1 promote epithelialmesenchymal transition of colorectal cancer via NF-B signaling, J. Surg. Oncol. 114 (2016) 520-527.

[55] L. Kalaydjieva, D. Gresham, R. Gooding, L. Heather, F. Baas, R. de Jonge, K. Blechschmidt, D. Angelicheva, D. Chandler, P. Worsley, A. Rosenthal, R.H. King, P.K. Thomas, N-myc downstream-regulated gene 1 is mutated in hereditary motor and sensory neuropathy-Lom, Am. J. Hum. Genet. 67 (2000) 47-58.

[56] R. Assamaki, M. Sarlomo-Rikala, J.A. Lopez-Guerrero, J. Lasota, L.C. Andersson, A. Llombart-Bosch, M. Miettinen, S. Knuutila, Array comparative genomic hybridization analysis of chromosomal imbalances and their target genes in gastrointestinal stromal tumors, Genes Chromosom. Cancer, 46 (2007) 564-576.

[57] A. Lorentzen, C. Mitchelmore, NDRG2 gene copy number is not altered in colorectal carcinoma, World J. Clin. Oncol. 8 (2017) 67-74.

[58] S.N. Hong, S.J. Kim, E.R. Kim, D.K. Chang, Y.H. Kim, Epigenetic silencing of NDRG2 promotes colorectal cancer proliferation and invasion, J. Gastroenterol. Hepatol. (Australia) 31 (2016) 164-171.

[59] A. Piepoli, R. Cotugno, G. Merla, A. Gentile, B. Augello, M. Quitadamo, A. Merla, A. Panza, M. Carella, R. Maglietta, A. D'Addabbo, N. Ancona, S. Fusilli, F. Perri, A. Andriulli, Promoter methylation correlates with reduced NDRG2 expression in advanced colon tumour, BMC Medical Genomics, 2 (no pagination), (2009).

[60] A.J. Wilson, A.C. Chueh, L. Togel, G.A. Corner, N. Ahmed, S. Goel, D.S. Byun, S. Nasser, M.A. Houston, M. Jhawer, H.J. Smartt, L.B. Murray, C. Nicholas, B.G. Heerdt, D. Arango, L.H. Augenlicht, J.M. Mariadason, Apoptotic sensitivity of colon cancer cells to histone deacetylase inhibitors is mediated by an Sp1/Sp3activated transcriptional program involving immediate-early gene induction, Cancer Res. 70 (2010) 609-620.

[61] A. Yamamura, K. Miura, H. Karasawa, K. Abe, Y. Mizuguchi, G. Jin, Z. Gu, S. Fukushige, N. Kaneko, M. Kinouchi, T. Ando, N. Yazaki, N. Tanaka, T. Sase, C. Shibata, I. Sasaki, A. Horii, Expression of the N-myc downstream-regulated gene 2 (NDRG2) is frequently suppressed by promoter hypermethylation in human gastrointestinal and pancreatic cancers, Cancer Research. Conference: 101st Annual Meeting of the American Association for Cancer Research, AACR, 2010, p. 70 .

[62] S.K. Park, C.S. Song, H.J. Yang, Y.S. Jung, K.Y. Choi, D.H. Koo, K.E. Kim, K.U. Jeong, H.O. Kim, H. Kim, H.K. Chun, D.I. Park, Field cancerization in sporadic colon cancer, Gut Liver 10 (2016) 773-780.

[63] H.Z. Zou, H. Allawi, X.M. Cao, M. Domanico, J. Harrington, W.R. Taylor, T. Yab, D.A. Ahlquist, G. Lidgard, Quantification of methylated markers with a multiplex methylation-specific technology, Clin. Chem. 58 (2012) 375-383.

[64] T.R. Levin, D.A. Corley, C.D. Jensen, A.R. Marks, W.K. Zhao, A.M. Zebrowski, V.P. Quinn, L.W. Browne, W.R. Taylor, D.A. Ahlquist, G.P. Lidgard, B.M. Berger, Genetic Biomarker Prevalence Is Similar in Fecal Immunochemical Test Positive and Negative Colorectal Cancer Tissue, Digestive diseases and sciences, 62 (2017), pp. 678-688.

[65] D.A. Ahlquist, W.R. Taylor, D.W. Mahoney, H.Z. Zou, M. Domanico, S.N Thibodeau, L.A. Boardman, B.M. Berger, G.P. Lidgard, The Stool DNA Test Is More Accurate Than the Plasma Septin 9 Test in Detecting Colorectal Neoplasia, Clin. Gastroenterol. Hepatol., 10 (2012) 272-U182.

[66] D. Redwood, E.D. Asay, P. Sacco, C.E. Hamlin, E. Otto, C. Christensen, P.W. Davis, J.J. Tiesinga, F.D. Sacco, M.E. Devens, S.R. Alberts, D.W. Mahoney, M.H. Fiero, T.C. Yab, G.P. Lidgard, B.M. Berger, E. Provost, D.A. Ahlquist, Stool DNA testing for screen-detection of colorectal neoplasia in Alaska native people, Gastroenterology 1 (2014) S-403.

[67] J.B. Kisiel, H.T. Allawi, P. Klepp, T. Sander, W.R. Taylor, T.C. Yab, S.A. Brackmann, A. Roseth, B. Moum, D.W. Mahoney, G.P. Lidgard, D.A. Ahlquist, Novel stool DNA markers for inflammatory bowel disease associated colorectal cancer and high grade dysplasia: High specificity across three independent international populations, Gastroenterology (1) (2016) S48.

[68] P. Klepp, H.T. Allawi, M.C. Smastuen, L.G. Lyckander, A. Roseth, S.N. Andersen, A. Tollisen, G.P. Lidgard, T. Sander, B. Moum, M.H. Vatn, J.B. Kisiel, D.A. Ahlquist, S.A. Brackmann, Stool DNA markers for the detection of neoplasia in patients with longstanding inflammatory bowel disease, Gastroenterology (1) (2016) S185-S186.

[69] G.P. Lidgard, M.J. Domanico, J.J. Bruinsma, J. Light, Z.D. Gagrat, R.L. OldhamHaltom, K.D. Fourrier, H. Allawi, T.C. Yab, W.R. Taylor, J.A. Simonson, M. Devens, R.I. Heigh, D.A. Ahlquist, B.M. Berger, Clinical performance of an automated stool DNA assay for detection of colorectal neoplasia, Clin. Gastroenterol. Hepatol. 11 (2013) 1313-1318.

[70] V. Melotte, J.M. Yi, M. Lentjes, K.M. Smits, L. Van Neste, H.E.C. Niessen, K.A.D. Wouters, J. Louwagie, K.E. Schuebel, J.G. Herman, S.B. Baylin, W. van Criekinge, G.A. Meijer, N. Ahuja, M. van Engeland, Spectrin Repeat Containing Nuclear Envelope 1 and Forkhead Box Protein E1 Are Promising Markers for the Detection of Colorectal Cancer in Blood, Cancer Prev. Res. 8 (2015) 157-164.

[71] X. Wangpu, X. Yang, J. Zhao, J. Lu, S. Guan, J. Lu, Z. Kovacevic, W. Liu, L. Mi, R. Jin, J. Sun, F. Yue, J. Ma, A. Lu, D.R. Richardson, L. Wang, M. Zheng, The 
metastasis suppressor, NDRG1, inhibits "stemness" of colorectal cancer via downregulation of nuclear beta-catenin and CD44, Oncotarget (6) (2015) 33893-33911.

[72] T.P. Ellen, Q. Ke, P. Zhang, M. Costa, NDRG1, a growth and cancer related gene: regulation of gene expression and function in normal and disease states, Carcinogenesis 29 (2008) 2-8.

[73] Z. Kovacevic, D.R. Richardson, The metastasis suppressor, Ndrg-1: A new ally in the fight against cancer, Carcinogenesis 27 (2006) 2355-2366.

[74] L. Yao, J. Zhang, X. Liu, NDRG2: a Myc-repressed gene involved in cancer and cell stress, Acta Biochim. Biophys. Sin. Shanghai 40 (2008) 625-635.

[75] W. Hu, C. Fan, P. Jiang, Z. Ma, X. Yan, S. Di, S. Jiang, T. Li, Y. Cheng, Y. Yang, Emerging role of $\mathrm{N}$-myc downstream-regulated gene 2 (NDRG2) in cancer, Oncotarget 7 (2016) 209-223.

[76] X. Yang, L. An, X. Li, NDRG3 and, two novel tumor-related genes, Biomed. Pharmacother. 67 (2013) 681-684.

[77] K.T. Kim, P.P. Ongusaha, Y.K. Hong, S.K. Kurdistani, M. Nakamura, K.P. Lu, S.W. Lee, Function of Drg1/Rit42 in p53-dependent mitotic spindle checkpoint, J. Biol. Chem., 279 (2004) 38597-38602.

[78] S. Stein, E.K. Thomas, B. Herzog, M.D. Westfall, J.V. Rocheleau, R.S. Jackson, M. Wang, P. Liang, NDRG1 is necessary for p53-dependent apoptosis, J. Biol. Chem. 279 (2004) 48930-48940.

[79] A.H. Zhang, J.N. Rao, T.T. Zou, L. Liu, B.S. Marasa, L. Xiao, J. Chen, D.J. Turner, J.Y. Wang, p53-Dependent NDRG1 expression induces inhibition of intestinal epithelial cell proliferation but not apoptosis after polyamine depletion, Am. J. Phys. Cell Phys. 293 (2007) C379-C389.

[80] G. Ambrosini, S.L. Seelman, G.K. Schwartz, Differentiation-Related Gene-1 Decreases Bim Stability by Proteasome-Mediated Degradation, Cancer Res., 69 (2009) 6115-6121.

[81] Y.J. Kim, S.Y. Yoon, J.T. Kim, S.C. Choi, J.S. Lim, J.H. Kim, E.Y. Song, H.G. Lee, I. Choi, J.W. Kim, NDRG2 suppresses cell proliferation through down-regulation of AP-1 activity in human colon carcinoma cells, Int. J. Cancer 124 (2009) 7-15.

[82] A. Golestan, Z. Mojtahedi, G. Ghalamfarsa, M. Hamidinia, M.A. Takhshid, The effects of NDRG2 overexpression on cell proliferation and invasiveness of SW48 colorectal cancer cell line, Iran. J. Med. Sci. 40 (2015) 430-439.

[83] K.C. Park, D.C. Lee, Y.I. Yeom, NDRG3-mediated lactate signaling in hypoxia, BMB Rep. 48 (2015) 301-302.

[84] Z. Chen, D. Zhang, F. Yue, M. Zheng, Z. Kovacevic, D.R. Richardson, The iron chelators Dp44mT and DFO inhibit TGF-beta-induced epithelial-mesenchymal transition via up-regulation of N-Myc downstream-regulated gene 1 (NDRG1), J. Biol. Chem. 287 (2012) 17016-17028.

[85] Z. Kovacevic, Z. Chen, J. Sun, D. Zhang, D.R. Richardson, Novel thiosemicarbazone iron chelators inhibit epithelial to mesenchymal transition and migration of cancer cells via the iron regulated metastasis suppressor ndrg1, Am. J. Hematol. 88 (5) (2013) E17-E18.

[86] R.S. Jin, W.S. Liu, S. Menezes, F. Yue, M.H. Zheng, Z. Kovacevic, D.R. Richardson, The metastasis suppressor NDRG1 modulates the phosphorylation and nuclear translocation of beta-catenin through mechanisms involving FRAT1 and PAK4, J. Cell Sci. 127 (2014) 3116-3130.

[87] L. Mi, F. Zhu, X. Yang, J. Lu, Y. Zheng, Q. Zhao, X. Wen, A. Lu, M. Wang, M. Zheng, J. Ji, J. Sun, The metastatic suppressor NDRG1 inhibits EMT, migration and invasion through interaction and promotion of caveolin-1 ubiquitylation in human colorectal cancer cells, Oncogene 36 (2017) 4323-4335.

[88] W.S. Liu, F. Yue, M.H. Zheng, A. Merlot, D.H. Bae, M. Huang, D. Lane, P. Jansson, G. Liu, V. Richardson, S. Sahni, D. Kalinowski, Z. Kovacevic, D.R. Richardson, The proto-oncogene c-Src and its downstream signaling pathways are inhibited by the metastasis suppressor, NDRG1, Oncotarget 6 (2015) 8851-8874.
[89] X.Z. Wangpu, J.Y. Lu, R.X. Xi, F. Yue, S. Sahni, K.C. Park, S. Menezes, M.L.H. Huang, M.H. Zheng, Z. Kovacevic, D.R. Richardson, Targeting the Metastasis Suppressor, N-Myc Downstream Regulated Gene-1, with Novel Di-2Pyridylketone Thiosemicarbazones: Suppression of Tumor Cell Migration and CellCollagen Adhesion by Inhibiting Focal Adhesion Kinase/Paxillin Signaling, Mol. Pharmacol. 89 (2016) 521-540.

[90] L. Shen, X. Qu, Y. Ma, J. Zheng, D. Chu, B. Liu, X. Li, M. Wang, C. Xu, N. Liu, L. Yao, J. Zhang, Tumor suppressor NDRG2 tips the balance of oncogenic TGF-beta via EMT inhibition in colorectal cancer, Oncogene (2014) 3.

[91] J. Hwang, Y. Kim, H.B. Kang, L. Jaroszewski, A.M. Deacon, H. Lee, W.C. Choi, K.J. Kim, C.H. Kim, B.S. Kang, J.O. Lee, T.K. Oh, J.W. Kim, I.A. Wilson, M.H. Kima, Crystal structure of the human N-Myc downstream-regulated gene 2 protein provides insight into its role as a tumor suppressor, J. Biol. Chem. 286 (2011) $12450-12460$

[92] X.Y. Xu, J.Y. Li, X. Sun, Y. Guo, D.K. Chu, L. Wei, X. Li, G.D. Yang, X.P. Liu, L.B. Yao, J. Zhang, L. Shen, Tumor suppressor NDRG2 inhibits glycolysis and glutaminolysis in colorectal cancer cells by repressing c-Myc expression, Oncotarget (6) (2015) 26161-26176.

[93] A. Suzuki, T. Ogura, H. Esumi, NDR2 acts as the upstream kinase of ARK5 during insulin-like growth factor-1 signaling, J. Biol. Chem. 281 (2006) 13915-13921.

[94] Y.J. Kim, H.B. Kang, H.S. Yim, J.H. Kim, J.W. Kim, NDRG2 positively regulates Ecadherin expression and prolongs overall survival in colon cancer patients, Oncol. Rep. 30 (2013) 1890-1898.

[95] J.T. Kim, J.W. Kim, Y.H. Kang, K.D. Kim, S.J. Lee, S.C. Choi, K.S. Kim, S.K. Chae, J.W. Kim, J.S. Lim, H.G. Lee, NDRG2 and PRA1 interact and synergistically inhibit T-cell factor/beta-catenin signaling, FEBS Lett. 586 (2012) 3962-3968.

[96] Y. Xing, B. Tang, C. Zhu, W. Li, Z. Li, J. Zhao, W.D. Gong, Z.Q. Wu, C.C. Zhu, Y.Q. Zhang, N-myc downstream-regulated gene 4, up-regulated by tumor necrosis factor-alpha and nuclear factor kappa B, aggravates cardiac ischemia/reperfusion injury by inhibiting reperfusion injury salvage kinase pathway, Basic Res. Cardiol. 111 (2016).

[97] G. Rademakers, N. Vaes, S. Schonkeren, A. Koch, K.A. Sharkey, V. Melotte, The role of enteric neurons in the development and progression of colorectal cancer, Biochim. Biophys. Acta 1868 (2017) 420-434.

[98] P.C. Havugimana, G.T. Hart, T. Nepusz, H. Yang, A.L. Turinsky, Z. Li, P.I. Wang, D.R. Boutz, V. Fong, S. Phanse, M. Babu, S.A. Craig, P. Hu, C. Wan, J. Vlasblom, V.U. Dar, A. Bezginov, G.W. Clark, G.C. Wu, S.J. Wodak, E.R. Tillier, A. Paccanaro, E.M. Marcotte, A. Emili, A census of human soluble protein complexes, Cell 150 (2012) 1068-1081.

[99] R.P. Kotipatruni, D.J. Ferraro, X. Ren, R.P. Vanderwaal, D.K. Thotala, D.E. Hallahan, J.J. Jaboin, NDRG4, the N-Myc downstream regulated gene, is important for cell survival, tumor invasion and angiogenesis in meningiomas, Integr. Biol. (Camb) 4 (2012) 1185-1197.

[100] R.P. Kotipatruni, X. Ren, D. Thotala, J.J. Jaboin, NDRG4 is a novel oncogenic protein and p53 associated regulator of apoptosis in malignant meningioma cells, Oncotarget 6 (2015) 17594-17604.

[101] S.H. Schilling, A.B. Hjelmeland, D.R. Radiloff, I.M. Liu, T.P. Wakeman, J.R. Fielhauer, E.H. Foster, J.D. Lathia, J.N. Rich, X.F. Wang, M.B. Datto, NDRG4 Is Required for Cell Cycle Progression and Survival in Glioblastoma Cells, J. Biol. Chem. 284 (2009) 25160-25169.

[102] S. Hongo, T. Watanabe, K. Takahashi, A. Miyazaki, Ndrg4 enhances NGF-induced ERK activation uncoupled with Elk-1 activation, J. Cell. Biochem. 98 (2006) 185-193.

[103] S. Nishimoto, J. Tawara, H. Toyoda, K. Kitamura, T. Komurasaki, A novel homocysteine-responsive gene, smap8, modulates mitogenesis in rat vascular smooth muscle cells, Eur. J. Biochem. 270 (2003) 2521-2531. 